\title{
Los jóvenes, la política y los movimientos estudiantiles en el Chile reciente. Ciclos sociopolíticos entre 1967 y 2017
}

\author{
Young people, politics and student movements in recent Chile. Sociopolitical \\ cycles between 1967 and 2017
}

Víctor Muñoz Tamayo * Carlos Durán Migliardi **

Resumen: El objetivo de este artículo es el desarrollo de una propuesta de periodización de los principales ciclos posibles de observar en la deriva de los movimientos juvenil-estudiantil chilenos, desde la década de los sesenta del siglo pasado hasta nuestros días. Desarrollado desde el enfoque de la Historia Reciente, la hipótesis que proponemos es que dichos ciclos se encuentran definidos por la forma en que estos movimientos han asumido su vínculo con la política y con el espacio político-institucional.

Palabras clave: Historia política, Chile, Movimiento estudiantil, Juventud.

\begin{abstract}
The objective of this article is the development of a proposal of periodization of the main possible cycles to observe in the drift of the Chilean youth-student movements, from the sixties of the last century to the present day. Developed from the perspective of Recent History, the hypothesis we propose is that these cycles are defined by the way in which these movements have assumed their link with politics and the political-institutional space.
\end{abstract}

Keywords: Political History, Chile, Students Movement, Youth.

Recibido: 27 marzo 2018 Aceptado: 20 mayo 2018

\footnotetext{
* Chileno. Primer autor. Doctor en Estudios Latinoamericanos (UNAM). Investigador Centro de Estudios de la Juventud CEJU - Universidad Católica Silva Henríquez UCSH. vmunozta@gmail.com.

** Chileno. Segundo autor. Doctor en Investigación en Ciencias Sociales (FLACSO México). Investigador asociado Universidad de Los Lagos, Centro de Estudios del Desarrollo Regional CEDER. Santiago. carlos.duran@ulagos.cl
} 


\section{Introducción}

Juventud y política corresponden a categorías que refieren a realidades en constante cambio y definición. Del mismo modo en que las juventudes ${ }^{1}$ chilenas han cambiado junto con las condiciones sociales en las cuales éstas se insertan, ha ocurrido que los sentidos y lugares de la política se han ido modificando a la par de los cambios en los vínculos entre el Estado, las estructuras económicas y la sociedad ${ }^{2}$. Por lo mismo, la pregunta por los movimientos sociales juveniles $^{3}$ nos conecta con dichas transformaciones, pues lo político habita los movimientos y la política constituye, por su parte, una de las dimensiones que estos aspiran a definir.

En el caso específico de los movimientos juveniles, cabe destacar que éstos se han caracterizado por la ocurrencia en su interior de permanentes disputas por su conducción que involucran enfrentamientos entre diferentes formas de entender lo político, de configurar su propia identidad en torno a ello y de vincularse con las expresiones institucionales de la política. Es decir, la política en los movimientos juveniles ha operado como una dimensión problemática en torno a la cual se elaboran definiciones, prácticas, sentidos y lógicas de acción en permanente mutación. Sin lugar a dudas, hay en ello condicionantes estructurales definidas principalmente desde la configuración del Estado y el sistema político, un campo institucionalizado cuyas relaciones determinan oportunidades y restricciones para los movimientos. Pero, al mismo tiempo, la historia también nos muestra que los movimientos sociales generan oportunidades y acceden a transformar las condicionantes asociadas al amplio campo de la política, sus sentidos y significados otorgados. ${ }^{4}$

Ahora bien, y en lo que refiere al caso específico de Chile, durante el siglo XX las actorías sociopolíticas de los jóvenes se expresaron fundamentalmente en el mundo estudiantil, pues si bien es verificable la presencia de jóvenes partícipes del movimiento obrero o del movimiento poblacional -entre otros espacios colectivos-, no existió en estos una transmisión identitaria que relevara lo juvenil por sobre las referidas condicionantes estructurales. En ese marco, fue prolífica la emergencia de liderazgos e iniciativas políticas que se expandieron en universidades y colegios al calor de movimientos sociales juveniles, alcanzando muchas veces

\footnotetext{
${ }^{1}$ Se entenderá la juventud como una categoría heterogénea, plural (“juventudes”) e histórica, que da cuenta de dimensiones sociales, biológicas y vitales que permanecen interrelacionadas y en tensión respecto a la definición de una edad señalada como intermedia entre una niñez y una adultez (también definidas según esos aspectos). Sobre esto, véase Mario Margulis y Marcelo Urresti, "La juventud es más que una palabra”, en Mario Margulis, La juventud es más que una palabra. Ensayos sobre cultura y juventud, Buenos Aires, Editorial Biblos, 1996, 13-30.

2 Respecto a la forma en que comprendemos el concepto de "lo político", para los efectos de este trabajo lo asumimos como un concepto que refiere a una dinámica que vincula lo institucional (la política entendida como ejercicio del poder estatal) con la contingencia de lo social, entendida esta última como la disputa por el establecimiento del "sentido" de lo social en un marco de permanente antagonismo. Sobre esto, véase Ernesto Laclau. La Razón Populista, Buenos Aires, FCE, 2005.

3 Cabe consignar, para los efectos del alcance de este trabajo, que la noción de "movimientos sociales" la utilizamos obviando su deriva conceptual. En otras palabras, en este trabajo optamos por evadir expresamente el debate conceptual en torno a su significado, utilizándolo más bien como una noción referida a fenómenos históricos de movilización social contenciosa.

4 Ver: Sidney Tarrow. El poder en movimiento: Los movimientos sociales, la acción colectiva y la política, Madrid, Alianza Editorial, 1998.
} 
un fuerte protagonismo en la escena nacional. ${ }^{5}$ Fue así como, por ejemplo, durante las décadas del 20 y 30 surgieron en los centros de estudio -particularmente universitarios- liderazgos y tendencias que luego confluyeron en la formación del Partido Socialista de Chile y la Democracia Cristiana, del mismo modo como, entre 1960 y 1973, se fraguaron en los campus movimientos revisionistas que alteraron la configuración de la izquierda, el centro y la derecha política, a partir de experiencias tales como las del Movimiento de Izquierda Revolucionaria MIR, el Movimiento de Acción Popular Unitaria MAPU o el Movimiento Gremialista (cuyo tránsito histórico desembocó hacia 1983 en el partido de derecha Unión Demócrata Independiente) ${ }^{6}$. Y es que los años sesenta y principios de los setenta fueron, de hecho, de gran politización juvenil, primero con clara hegemonía de la Democracia Cristiana, y luego como expresión del crecimiento de la izquierda.

Entre 1973 y el presente, la condición juvenil - estudiantil ha cambiado en relación directa con las características del modelo neoliberal. Así mismo, la política también ha mutado, tanto en su vínculo con las instituciones del Estado y el sistema de partidos, como en su relación con los movimientos sociales, particularmente los movimientos sociales juveniles.

Desde las ciencias sociales, el abordaje del vínculo entre juventud y política durante el periodo acá tratado ha estado mediado por las transformaciones contemporáneas en los vínculos entre Estado, sociedad y economía. ${ }^{7}$ Durante los años sesenta, en primer lugar, la producción sobre jóvenes buscó entender el posicionamiento de las nuevas generaciones ante las alternativas de cambio revolucionario que proponían la izquierda y el centro demócrata cristiano, lo que motivó la interrogante dicotómica con la que se titula el estudio de Armand y Michele Mattelard: "Juventud chilena: Rebeldía o conformismo". ${ }^{8}$ Los Mattelard, a partir de la pregunta en torno a si "los jóvenes" eran rebeldes o conformistas, buscaron derribar mitos totalizadores sobre este grupo etario, los que iban desde la etiqueta de "inadaptados" hasta el diagnóstico de un "poder joven" de características revolucionarias como condición intrínseca a la edad. Sus tesis apostaron por complejizar la mirada sobre los jóvenes desde una lectura que enfatizaba en las distinciones que contenía la juventud en relación a su inserción estructural y su cercanía concreta con instancias de politización, principalmente partidos, federaciones estudiantiles y sindicatos.

Tras el golpe de Estado, durante los años de la dictadura el debate estuvo marcado por entender las actorías juveniles en los contextos de protesta antidictatorial, crisis económica y cierre autoritario de los canales de participación. Entonces, destacaron dos tipos de abordajes. Por un lado, las miradas que diagnosticaron anomia social (concepto que Durkheim usara para referirse a la desintegración de las normas que mantienen la cohesión social), particularmente

\footnotetext{
5 Ver: Manuel Antonio Garretón y Javier Martínez (editores), Biblioteca del movimiento estudiantil, Santiago, Sur Profesionales, 1985. Gabriel Salazar y Julio Pinto, Historia Contemporánea de Chile V. Niñez y Juventud, Santiago, Lom, 2002.

${ }^{6}$ Ver: Cristina Moyano, MAPU o la seducción del poder y la juventud, Santiago, Ediciones UAH, 2009; Eugenia Palieraki, "iLa revolución ya viene! El MIR chileno en los años sesenta”, Santiago, LOM, 2014; Verónica Valdivia, Nacionales y Gremialistas. El parto de la nueva derecha política chilena 1964 1973, Santiago, LOM, 2008.

7 Un tratamiento más detallado sobre la producción de las ciencias sociales en torno al vínculo juventud y político entre los años 60 y el presente, en: Víctor Muñoz Tamayo y Oscar Aguilera, "Preguntas por la juventud, preguntas por la política. Acción colectiva, movimientos sociales y militancia en los estudios de juventud. Chile 1967 2013”, Pablo Cottet editor, Juventudes. Metáforas del Chile contemporáneo, Sanriago, RIL, 2015, 69-103.

${ }^{8}$ Armand y Michele Mattelard, Juventud chilena: rebeldia y conformismo, Santiago, Edición Universitaria, 1970.
} 
en los jóvenes populares, en tanto rebeldía que expresaría fundamentalmente rabia y desesperanza sin mayores alternativas políticas ni conducentes a fines específicos ${ }^{9}$. Por otro lado, quienes planteaban que los sujetos juveniles, pese a las condicionantes estructurales del orden autoritario y neoliberal, sí realizaban esfuerzos concretos por articular una voz y una acción con sentidos políticos. En conclusión, esta última perspectiva entendió la juventud tanto como colectivo receptor de castigo y exclusión por parte de la dictadura, como en tanto agente capaz de articular una "acción juvenil" que enfrentó las orientaciones de la dominación. ${ }^{10}$

Hacia los años de la transición, las ciencias sociales asumieron la pregunta en torno a cómo articular juventud y política en el contexto de la democracia naciente, con todos sus límites y problemas. En ese sentido, hubo una gran producción en torno a los "problemas de la juventud" o aquello que hacía a los jóvenes principales acreedores de una deuda social, y en este caso, de una deuda relativa a la exclusión política. ${ }^{11}$ Paralelamente, se buscó aportar en el debate de políticas públicas que promovieran un sujeto/actor juvenil, en tanto capaz de actuar ante el conflicto social, haciendo real la democratización, pues una de las tesis fue que de no potenciarse esta conversación social, la conflictividad desembocaría en malestares violentos ante un orden percibido como ajeno y omnipotente. ${ }^{2}$ Por último, en relación a lo que se ha entendido como recientes procesos de politización del malestar juvenil, se han desarrollado reflexiones centradas en describir la forma en que, desde las movilizaciones estudiantiles del año 2011, diversos espacios de acción juvenil han traducido su acción hacia la disputa política $\mathrm{y}$, recientemente, hacia la disputa político-institucional. ${ }^{13}$

En lo que refiere al campo de la historia reciente, el grueso de la producción ha estado orientado a la comprensión del movimiento estudiantil -sobretodo universitario- entre 1973 y la década de los noventa. Ahí, destacan autores como Garretón, Toro, Muñoz, Thielemann y Moraga, y Aguilera en el caso específico de los estudiantes secundarios. ${ }^{14}$ Aunque con énfasis diferentes, la totalidad de las aproximaciones coinciden en tratar al movimiento estudiantil en interacción conflictiva con el Estado, marcado por la relación del sistema educativo con el mercado, y en vínculo con las militancias políticas inscritas en contextos, estructuras, lecturas de la realidad o "imperativos nacionales" (como lo plantearan Toro, Islas y García). En este

\footnotetext{
${ }_{9}^{9}$ El texto más importante en esta línea fue: Eduardo Valenzuela, La rebelión de los jóvenes. Un estudio de anomia social, Santiago, Ediciones Sur, 1984.

${ }^{10}$ En esta línea destaca el conjunto de autores presentes Irene Agurto, Manuel Canales, Gonzalo De la Maza (compiladores), Juventud chilena. Razones y subversiones, Santiago. Eco, Folico, Sepade, 1985.

${ }^{11}$ Generación compiladores, Los jóvenes en Chile hoy, CIDE, CIEPLAN, INCH, PSI PIRQUE, SUR. Santiago 1990.

12 Pablo Cottet y Lidgia Galvan, Jóvenes, una conversación por cambiar, Santiago, ECO, 1993.

13 Carlos Durán, "El acontecimiento estudiantil y el viraje del proceso sociopolítico chileno", en Observatorio social de América Latina, 31, CLACSO, Buenos Aires, 2012.

14 Garretón, op cit. Víctor Muñoz Tamayo, ACU. Rescatando el asombro. Historia de la Agrupación Cultural Universitaria, Santiago, Calabaza del Diablo, 2006; Víctor Muñoz Tamayo, Generaciones. Juventud universitaria e izquierdas políticas en Chile y México (Universidad de Chile-UNAM 1984-2006), Santiago, LOM, 2011; Diego García Monge, José Isla, Pablo, Los muchachos de antes. Historia de la FECH 1973 - 1988, Santiago, Universidad Alberto Hurtado, 2006; Luis Thielemann, La anomalía de la transición. Movimiento estudiantil e izquierda universitaria en el Chile de los 90, Santiago, Tiempo Robado, 2016; Fabio Moraga Valle, "Crisis y recomposición del movimiento estudiantil chileno 1990- 2001"; Renate Marsiske, Movimientos estudiantiles en la bistoria de América Latina Ill, México DF, UNAM. Plaza y Valdés, 2006, 179- 252; Oscar Aguilera, Movidas, movilizaciones y movimientos: cultura política y politicas de las culturas juveniles en el Chile de hoy, Santiago, RIL, 2016.
} 
último sentido, se aborda el movimiento estudiantil a la par del análisis de los grupos de las izquierdas, centros y derechas estudiantiles.

Aunque estas últimas miradas han sido prolíficas en analizar diferentes momentos y procesos en los últimos 50 años de movimiento estudiantil, ninguna de ellas ha propuesto un criterio de periodificación que permita inscribir la diversidad de expresiones movimientales juveniles dentro de un marco histórico de mediana duración. Y es precisamente atendiendo a este déficit que, en este artículo, proponemos un análisis de los cambios en la condición juvenil (que incorpore y se centre en lo estudiantil, pero que vaya más allá de ella) y su conexión con la política. Para esto, exponemos lo que a nuestro juicio corresponde a seis ciclos posibles de observar entre 1967 y 2017. Cada ciclo tiene sus propios ejes que lo definen, y su inicio y fin se asocia a determinados quiebres y transformaciones que abarcan todo el complejo de relaciones intra- movimientos, al igual como las dinámicas de articulación entre estos, la sociedad y el sistema político. Nuestro objetivo, así, es ofrecer un criterio de periodización del vínculo entre juventud y política, asumiendo su articulación como un proceso en que ambos componentes se encuentran en constante construcción a partir de su interrelación con el entorno social.

En definitiva, el propósito de este trabajo es exponer a modo de ensayo y siguiendo los principios de la sociología histórica ${ }^{15}$, un criterio de periodización de la relación entre movimiento juvenil y contexto político en el Chile de las últimas cinco décadas. Buscamos, así, abrir el debate acerca de la deriva de los movimientos estudiantil-juveniles en el Chile de los últimos 50 años, proponiendo que sus distintas etapas se encuentran definidas en sus distintas formas de vinculación con lo político.

Por último, cabe señalar que este ensayo se encuentra elaborado a partir de la revisión de la literatura secundaria producida en relación al tema desde el campo de la sociología y de la historiografía. Las referencias a eventos e hitos específicos, por consecuencia, solo es considerada en este trabajo para efectos de abordar la problemática de la periodización de los movimientos juveniles - estudiantiles chilenos.

\section{Ciclo 1- 1967 - 1973. Lucha en torno a los escenarios, las posibilidades y los límites de la política}

Durante los años sesenta, la sociedad chilena se volcó mayoritariamente hacia proyectos políticos que propusieron transformaciones estructurales en el país, de modo que los discursos que apelaban al cambio revolucionario predominaban en el parlamento y en las organizaciones sociales de base. La DC triunfante en 1964 llevó su discurso de "Revolución en libertad" a la oficialidad gobernante, lo que en la práctica significó cuestiones como revisar el derecho de propiedad para impulsar la reforma agraria, ampliar los derechos sindicales hacia el mundo campesino y promover la organización de los pobladores.

Mientras tanto, la izquierda institucionalizada se propuso acelerar los cambios socioeconómicos hacia el establecimiento de un sistema socialista en Chile, para lo cual buscó

\footnotetext{
${ }^{15}$ Este trabajo recoge de la sociología histórica su interés por articular la lógica narrativa propia de la historiografía con la estrategia analítica que caracteriza la aproximación sociológica a los fenómenos sociales. Es decir, la búsqueda por abordar la singularidad de los procesos históricos sin perder de vista el objetivo analítico de reducción conceptual. Sobre esta forma de abordaje y sus dilemas, véase Ramón Ramos, "Problemas textuales y metodológicos de la sociología histórica”, Reis, vol. 63, n. 93, 1993.
} 
distinguirse del centro reformista de la DC y así triunfar en los dos campos que había considerado esenciales: los movimientos sociales y la movilización electoral. Influenciada por la revolución cubana de 1959, emergió a mitad de los sesenta otra izquierda que se llamó así misma "revolucionaria" y que actuó desde lo que entendió como una certeza básica: el camino al socialismo era, y solo podía ser, el insurreccional, por lo que rechazaba el camino parlamentario-electoral y apostaba por un poder popular que, configurado desde los movimientos sociales y con incorporación de la lucha armada, terminara desbordando una institucionalidad que se acusaba de "burguesa". Hubo jóvenes presentes en todas estas posiciones y, en general, los discursos orientados a la transformación tendieron a dar valor a la voluntad expresada en un poder joven movilizado, por lo que obtener triunfos en federaciones estudiantiles fue una prioridad para los partidos políticos.

Dichos partidos, insertos o no en las lógicas formales de la política parlamentaria, fueron en esos años los grandes referentes identitarios del activismo político juvenil, y se entendió que desde ellos se operaba en tanto vanguardia u orgánica que debía pugnar por la conducción de los movimientos sociales. La presencia juvenil estuvo de modo significativo en todas estas identidades políticas, pero fue particularmente clara en las corrientes radicalizadas impulsadas por la generación socializada bajo la influencia de las corrientes guerrilleras latinoamericanas, es decir, partidos como el MIR -nacido desde sumatoria de corrientes, en especial de facciones juveniles del PS- y el MAPU, cuya primera división alejó a los cuadros dirigentes de más edad (que rechazaron ser un partido marxista leninista y formaron la izquierda Cristiana), y cuya segunda división separó a la corriente más moderada de aquella más radicalizada. ${ }^{16}$

Como dijimos, jóvenes hubo en muchos frentes de organización, pero la identidad específicamente juvenil se enarboló particularmente desde el movimiento estudiantil. Y en ese sentido, los movimientos vinculados al proceso de reforma universitaria durante los años sesenta debemos entenderlos como vínculos entre proyectos de cambio sectorial y apuestas de cambio político socio-estructural. En estos movimientos reformistas, se reclamaba una administración más eficiente de los recursos económicos y humanos, así como terminar con el carácter elitista de la educación superior, asegurar el pluralismo de ideas y dar participación en las decisiones administrativas a todos los actores de la universidad. Pero estos objetivos de modernización y democratización trascendían lo estrictamente académico y se valoraban en tanto acompañamiento de procesos modernizadores-desarrollistas y democrático-populares a impulsar a nivel general en la sociedad. El caso más paradigmático es el de la Universidad Católica, siendo 1967 el año en que su Federación de estudiantes FEUC, presidida por el independiente apoyado por la JDC Miguel Ángel Solar, se tomó la casa central de la universidad en el mes de agosto para exigir la renuncia de las autoridades y el nombramiento de "nuevos hombres" para la construcción de una "nueva universidad", iniciando un proceso de participación de los estudiantes en instancias de gobierno universitario.

La politización explícita de los movimientos reformistas universitarios tuvo también un rechazo organizado en la UC, donde universitarios que venían de identificarse con la derecha conservadora estaban sumamente decepcionados de dicha derecha, en la que creían ver un actuar pusilánime ante el avance de la izquierda y el accionar reformador de la Democracia Cristiana. Tal sensibilidad, que se denominó a sí misma como "gremialista", rechazó lo que

${ }^{16}$ Moyano, op. cit. 
describía como un estado de excesiva politización de los campus universitarios, argumentando que la organización estudiantil -en este caso las federaciones- constituían cuerpos sociales intermedios entre el hombre y el Estado, por lo que su finalidad en sociedad estaría estrictamente acotada a la realidad que los unía como particularidad social (en el caso de la universidad, la búsqueda del conocimiento y la verdad) y no podían pretender actuar en la disputa por la conducción del Estado, es decir, en la política.

Este movimiento apareció primero en la escuela de derecho de la UC, liderado por Jaime Guzmán, y se proyectó a toda la universidad hasta que el año 67 encabezaron una oposición estudiantil a las reformas, conquistando la presidencia de FEUC en 1968. Aunque el activismo de los gremialistas fue descrito por ellos como apolítico y contrario a la presencia de la política en los campus, fueron uno de los movimientos claves para la articulación social de la oposición al gobierno de Allende. Hacia 1973, los gremialistas pidieron la renuncia del presidente socialista, hicieron llamados directos a la intervención militar y plantearon la necesidad de una nueva institucionalidad política que marginara a las identidades marxistas. ${ }^{17}$ Coincidentes estas consignas con las del golpe de estado del 11 de septiembre, su líder Jaime Guzmán fue llamado inmediatamente a colaborar con el nuevo régimen y asumir roles protagónicos en tres tareas: organizar a la juventud, producir una propuesta de nueva constitución, y articular la propaganda del régimen. ${ }^{18}$

Mientras los cuadros gremialistas avanzaron rápidamente a la primera línea de protagonismo dictatorial, la juventud identificada con la izquierda fue fuertemente reprimida, sufriendo cárcel, muerte, desaparición, tortura y exilio. Por su parte, los jóvenes que permanecían plenamente identificados con el relato político demócrata cristiano actuaron sobre la base de un partido que, si bien no se volvió a quebrar (ya lo había hecho con el surgimiento del MAPU), estaba profundamente dividido entre quienes apostaron por una oposición férrea a Allende (en conjunto con la derecha) y quienes sostenían la idea de "ser una oposición revolucionaria a un gobierno revolucionario ${ }^{* 19}$. Tras el golpe, la misma división perduró entre quienes lo rechazaron e hicieron suya la declaración de 13 altos dirigentes partidarios en contra de la intervención militar, y los que optaron por resguardar, en silencio, la orgánica partidaria y no definirse como opositores. ${ }^{20}$ Los primeros recibieron el nombre de "chascones", a los segundos se les conocerá como "guatones".

La fractura del golpe marca de modo abrupto el fin de este ciclo político juvenil de sello politizador en que se debatió justamente los caminos, las posibilidades y los límites de la política. La dictadura, sobre todo en su primera etapa, tenderá más bien al rechazo de toda

\footnotetext{
17 Ver: Carta abierta de FEUC al presidente Allende. Documento firmado por el comité ejecutivo de FEUC: Javier Leturia, presidente; Alberto Hardessen, vicepresidente; Guillermo Correa, secretario general. Santiago, 3 de junio de 1973. Archivo Fundación Jaime Guzmán. Y: Hacia una nueva institucionalidad a través de la renuncia de Allende. Declaración de: Federación de Estudiantes de la Universidad Católica de Chile FEUC, Federación de Estudiantes de la Universidad Católica de Valparaíso FEUC- V. Santiago, 29 de agosto de 1973. Archivo Fundación Jaime Guzmán.

18 "Personalmente estoy trabajando full- time con el gobierno, manteniendo aparte únicamente mis clases en la Universidad. Colaboro en una comisión destinada a redactar una nueva constitución, y también en la organización de la propaganda y de la juventud, en la secretaría general de gobierno". En carta de Jaime Guzmán a su madre: Jaime Guzmán Errázuriz, Escritos personales, Santiago, Fundación Jaime Guzmán, 2008, op cit 91.

${ }^{19}$ Ver testimonios de Renán Fuentealba en: Alessandro Santoni, El comunismo italiano y la vía chilena. Los orígenes de un mito político, Santiago, Ril, 2011, op cit 172.

${ }^{20}$ Jorge Donoso y Grace Dunlop Echavarría, Los 13 del 13. Los DC contra el golpe, Santiago, Ril, 2013.
} 
actividad política, y promoverá la idea de una juventud despolitizada y sólo organizada desde lógicas autoritarias basadas en una idea de "unidad nacional" en torno al régimen. El ciclo termina cuando se pasa de la politicidad desbordada a la prohibición y persecución de la actividad política y su carácter de expresión pública de los conflictos sociales.

\section{Ciclo 2 - Apelación patriótica, apolítica y de unidad nacional, versus resistencia cultural 1973 - 1982}

El golpe militar supone una doble voluntad refundacional: por una parte, la construcción de una nueva institucionalidad política (nueva Constitución) de carácter autoritario y pluralismo limitado (lo que se llamó "nueva democracia" o "democracia protegida"), tarea en torno a la que el régimen define, en principio, "metas y no plazos", buscando legitimar la permanencia indefinida de la dictadura en post de dicho objetivo. Por otro lado, hacia la mitad de la década se consolida un enfoque neoliberal que pretende situar al libre mercado y la iniciativa económica privada como principal motor de la estructuración del orden social, velando porque el Estado asuma un rol subsidiario.

En concordancia con esta voluntad refundacional, los espacios de participación estudiantil fueron intervenidos y operó el mismo proceder represivo que imperaba en el país, sumándose a ello la constante expulsión de alumnos, la que redundó en una profunda crisis de sus espacios de acción colectiva. Las organizaciones del estudiantado fueron prohibidas o sus directivas designadas directamente por los órganos de gobierno o autoridades delegadas del régimen, que en caso de las universidades eran rectores militares.

En relación a la enseñanza media, durante este período se amplió la cobertura educativa -aunque fundamentalmente desde la oferta privada-, se planificó la municipalización de los colegios fiscales y se orientó el modelo a una profunda segmentación del sistema escolar mediante segregaciones por pago y selección académica. ${ }^{21}$ El sistema universitario también creció por vía de los privados, se incorporó a más jóvenes a las universidades, pero mediante el endeudamiento, lo que no garantizaba calidad de la educación dentro de un heterogéneo mercado educativo. Se implementaron también radicales cambios en el sistema de financiamiento universitario: se redujo el aporte del Estado a la educación superior, se comenzaron a cobrar matrículas en universidades que antes eran sin costo, en 1977 se implementó un "arancel diferenciado" por tramos socioeconómicos, y en 1981 se aplicaron los decretos leyes que conformaron la Ley General de Universidades, expresión definitiva del proceso de privatización del sistema universitario chileno. ${ }^{22}$

21 Ver Cristian Bellei, El gran experimento. Mercado y privatización de la educación chilena, Santiago, Lom, 2015.

22 Entre los principales componentes de la nueva ley de universidades es posible destacar la redefinición jerárquica de las carreras de educación superior, dejando doce títulos como exclusivamente universitarios y el resto a libre disposición para ser otorgados por institutos profesionales y centros de formación técnica; la orientación del crecimiento del sistema de educación superior hacia el sector privado; autofinanciamiento universitario, con lo que se le quitaba responsabilidad al Estado en el financiamiento de las universidades y se establecían cuotas de arancel sin criterios de diferenciación socioeconómica; sistema de crédito fiscal para los alumnos que certificaran ingresos familiares que no les permitiesen cancelar el total de los aranceles, postergándose el pago cuando el estudiante terminara o interrumpiera sus estudios; búsqueda por motivar la competencia entre centros académicos mediante la entrega de un subsidio a través de los 20000 mejores puntajes en la prueba única de ingreso a las universidades tradicionales; negación del espacio universitario para toda acción catalogada de "incompatible al 
Durante este período, si bien la actividad política fue prohibida en colegios y universidades, se desarrolló un tipo de militancia oficialista que giró en torno a los ejes discursivos de la unidad nacional: cierta efebolatría como pilar de la propaganda del gobierno (culto a lo joven y representación del régimen como proyección virtuosa de la juventud) y referencias patrióticas y estéticas vinculadas al enaltecimiento de los militares. ${ }^{23}$ En esta dirección, cuadros que habían surgido del llamado "movimiento gremialista" conducido por Jaime Guzmán, con el apoyo del organismo estatal Secretaría Nacional de la Juventud (SNJ, administrada por gremialistas), organizaron en 1975 el Frente Juvenil de Unidad Nacional (FJUN). Dicho referente, en coordinación con una red política informal encabezada por Guzmán, consolidó al gremialismo como uno de los principales grupos organizados de apoyo a la dictadura, lo que para algunos analistas significó que funcionara prácticamente como partido único del régimen. ${ }^{24} \mathrm{El}$ gremialismo fue también el que copó las designaciones en las directivas de las organizaciones estudiantiles intervenidas, de modo que en este periodo el actuar de centros de alumnos y federaciones fue de abierto apoyo al régimen, lo que fue justificado discursivamente como patriotismo apolítico.

En las universidades, la resistencia a la intervención militar se dio en primer término por la vía de un activismo artístico-cultural que extremó las posibilidades comunicativas del símbolo y la metáfora para construir mensaje opositor eludiendo la censura y la represión. Fue el momento de la proliferación de talleres culturales de teatro, literatura y plástica, destacando en la Universidad de Chile una red de estos talleres que se llamó Agrupación Cultural Universitaria. ${ }^{25}$ Fue también el momento en que, a partir de finales de la década del 70, estudiantes opositores fueron ganando espacios en la tarea de democratizar centros de alumnos por vía de elecciones abiertas, contraviniendo las prohibiciones y enfrentando por ello sanciones. Este activismo opositor de énfasis democratizador y artístico se relacionó con un proceso de rearticulación de los partidos políticos clandestinos.

Siguiendo una lógica sedimentada a lo largo del siglo $\mathrm{XX}$, los universitarios de oposición recorrieron dos caminos de reconstrucción orgánica, caminos paralelos con lógicas y referentes propios, pero también relacionados e imbricados: el de la militancia en partidos clandestinos y en las organizaciones del estudiantado, pues si bien había militantes enfocados en una u otra dimensión, era significativa la presencia del "doble militante" que compartía identidad con un partido y con organizaciones sociales de la juventud universitaria.

orden jurídico" o "actividad política"; fragmentación de las dos grandes universidades públicas nacionales, la Universidad Técnica y la Universidad de Chile; sistema de gobierno universitario basado en autoridades unipersonales que en última instancia dependían del poder político; negación de cualquier tipo de participación de los estamentos de académicos, estudiantes y funcionarios. Ver: Decreto con Fuerza de Ley N- 1 de 30 de diciembre de 1980, publicado en: Revista Academia número 1, Santiago, Academia Superior de Ciencias Pedagógicas, 1981.

${ }^{23}$ Ver: Víctor Muñoz Tamayo, "Chile es bandera y juventud. Efebolatría y gremialismo durante la primera etapa de la dictadura de Pinochet". (1973-1979)", Historia Crítica 54, Colombia, Universidad de los Andes, 2014,195 219. Yanko González, "El golpe generacional y la Secretaría Nacional de la Juventud: Purga, disciplinamiento y resocialización de las identidades juveniles bajo Pinochet (1973 - 1980), Atenea 512, Concepción, Universidad de Concepción, 2015, 87-111.

${ }^{24}$ Ver: Carlos Hunneus, El régimen de Pinochet, Santiago, Sudamericana, 2000. P 238.

25 Ver: Víctor Muñoz Tamayo, op cit. 
Situación similar se fue dando en los sectores poblacionales, fundamentalmente en Santiago, mediante la reconstrucción de la militancia política a la par del surgimiento de centros juveniles que gestionaban festivales y talleres de música, teatro, plástica y literatura, todo ello al alero del único espacio disponible a nivel local: la Iglesia Católica. Desde este lugar opositor, la política se entendía como espacio a construir a partir de la organización cotidiana y la militancia partidista clandestina, en una labor que vinculaba ambas dimensiones, y en donde los partidos buscaban llevar a la sociedad las perspectivas que estaban proyectando en torno a la dictadura y las estrategias para acabar con ella.

En definitiva, durante este ciclo operaron dos lógicas. Por un lado, la idea de apoyo al gobierno desde una organización de la juventud que, como vimos, fue una apuesta que el régimen encargó a los gremialistas y que tuvo un organismo articulador (SNJ), una expresión militante (el FJUN), y que operó administrando la representación autoritaria y designada de centros de alumnos y federaciones. Por otra, la recomposición del tejido social opositor en condiciones de extrema represión y vigilancia, con partidos políticos clandestinos y un activismo social que tuvo en el arte un instrumento privilegiado para los efectos de convocar, articular y comunicar discursos políticos de resistencia. El ciclo termina cuando el régimen experimenta su primera gran crisis política y económica; la oposición gana visibilidad y fortaleza orgánica al calor de la extensión de la protesta pública; y el movimiento estudiantil inicia una institucionalización democrática a contrapelo de los valores autoritarios.

\section{Ciclo 3. Democracia versus dictadura. La formalización política oficialista y los caminos de la sublevación, la protesta y la transición en la oposición.}

(1983-1989)

El año 1982, la crisis económica que fue conocida internacionalmente como "crisis de la deuda" golpeó al país. El alza del desempleo, las quiebras, la crisis bancaria y la forzosa devaluación del peso dañaron al régimen que intervino la banca como medida de salvataje e intentó frenar el aumento de los desempleados por la vía de planes públicos con sueldo mínimo. La primera consecuencia sociopolítica del desbarajuste económico fue la emergencia de la protesta social, primero convocada por sindicatos del cobre y luego anunciada también por partidos opositores que fueron adquiriendo mayor visibilidad pública. Como modo de contener la protesta social, la dictadura llamó a un viejo líder político de la derecha, Sergio Onofre Jarpa, que asumió el Ministerio del Interior, en la perspectiva de que éste abriera canales de diálogo con los grupos opositores más moderados. En ese contexto, la oposición debatía los caminos a seguir, algunos más inclinados a la movilización social (en un principio, desde la izquierda hasta sectores de la Democracia Cristiana) y otros a la búsqueda de una salida pactada (al inicio, fundamentalmente sectores de la DC, aunque luego se sumarían grupos moderados de izquierda); y dentro de los que apostaban por la movilización, algunos que priorizaban por la desobediencia civil pacífica (sectores de la DC y de la izquierda) y otros que incorporaban la lucha armada en tanto factor que apoyase una estrategia de derrocamiento de Pinochet mediante la sublevación de masas (la fracción socialista mayoritaria, el Partido Comunista y el Movimiento de Izquierda Revolucionaria MIR). Estas divisiones, hacia 1983 se expresaron a grandes rasgos en dos coaliciones opositoras: una fue la Alianza Democrática, sector moderado que reunía a las agrupaciones dialogantes y a las que priorizaban una 
movilización de masas sin violencia (la DC, grupos identificados con una derecha no pinochetista, grupos socialistas y el Partido Radical); y el Movimiento Democrático Popular, que aglutinaba a partidos de izquierda proclives a derrocar la dictadura por vía de la movilización de masas, sin dialogo conducente a pacto y con elementos insurreccionales (PC, fracción mayoritaria del PS que dirigía Clodomiro Almeyda y MIR).

En este contexto, el movimiento estudiantil opositor cambió sus ejes de acción, cerrando el ciclo centralizado en el activismo cultural y potenciando el horizonte democratizador y de lucha reivindicativa gremial contra las políticas de intervención y autofinanciamiento universitario. ${ }^{26}$ Ello, fundamentalmente a partir de la reestructuración de los organismos representativos del estudiantado, es decir, los centros de alumnos y las federaciones esta vez establecidas mediante elecciones universales y directas. ${ }^{27}$ Fue así como, a mediados de la década del ochenta, los universitarios opositores lograron desbancar a las representaciones gremiales designadas bajo el modelo de la intervención e implementaron elecciones democráticas que significaron el resurgimiento de las federaciones a lo largo de todo el territorio nacional. ${ }^{28}$

Paralelamente, en los colegios secundarios se avanzaba en la democratización de centros de alumnos y nacieron coordinaciones que permitieron la reestructuración de la histórica Federación de Estudiantes Secundarios FESES. Si bien el estudiantado movilizado tras estos esfuerzos era compuesto por masas militantes y no militantes con identidad anti dictatorial, lo cierto es que fueron las militancias políticas de los partidos opositores las que disputaron los cargos de las directivas de las federaciones, y cada candidato a federación era percibido como representante de una postura política y partido político determinado.

Para ese entonces, el cúmulo de expectativas cifradas en lo que implicaba el fin de la dictadura y las disyuntivas en torno a cómo llegar a ese fin, operaron como un imperativo político nacional, de modo que tanto el activismo estudiantil como las relaciones entre sus grupos fueron determinados por dicho imperativo y sus urgencias. ${ }^{29}$ En tal sentido, así como los activistas asumieron que las demandas gremiales no podían adquirir independencia de la lucha anti dictatorial, del mismo modo asumieron que las alianzas entre grupos estudiantiles necesariamente eran influenciadas por las afinidades y orientaciones generadas a nivel nacional por los partidos políticos. En ese marco, las elecciones de federación, con miles de votantes en el caso de las universidades, con candidatos explícitamente representativos de cada fuerza opositora, y en un país donde las elecciones nacionales y la política formal estaban prohibidas, fue un fenómeno que cobró el valor de barómetro político nacional, representando hitos de máximo interés y relevancia para el campo político opositor.

En relación a las redes organizadas de la juventud poblacional, estas confluyeron en las protestas a partir de $1983 .{ }^{30}$ En ese momento, se rompe con la imagen predominante del movimiento sociopolítico juvenil como sinónimo de movimiento estudiantil y aparece con

\footnotetext{
${ }^{26}$ Por cierto, sigue existiendo un activismo cultural, y no deja de hacerse política y movimiento estudiantil desde la cultura, pero ello no tiene la centralidad del ciclo anterior.

${ }^{27}$ Muñoz Tamayo, op. cit,, capítulos 2 y 4. García, Isla, Toro, op cit.

${ }^{28}$ Desde las federaciones de Santiago y regiones también se promovió la vinculación del movimiento estudiantil con otros sectores y movimientos a lo largo de todo el país, lo que se desarrolla, por ejemplo, desde iniciativas de trabajos voluntarios en zonas rurales, urbanas y con actores pobladores, campesinos y comunidades indígenas.

${ }^{29}$ García, Isla, Toro, op cit.

${ }^{30}$ Irene Agurto, Manuel Canales, Gonzalo De la Maza (compiladores), op cit.
} 
fuerza la imagen del joven poblador, aquel que es afectado por la cesantía y las expectativas frustradas de movilidad social a partir de la educación (como cantaran Los Prisioneros en "El baile de los que sobran"), pero que también puede ser actor y dirigir la protesta como voz de descontento antidictatorial en la década de 1980.

Paralelamente, la derecha también se organizó, el gremialismo formalizó la orgánica de facto que había ido sedimentando desde 1973, surgiendo la Unión Demócrata Independiente UDI bajo el liderazgo de Guzmán, su generación coetánea de los años sesenta (compuesta, entre otros, por Jovino Novoa), y aquella generación de líderes universitarios gremialistas formados por Guzmán entre la década del 70 y el 80 durante dictadura (como Juan Antonio Coloma, Andrés Chadwick, Pablo Longueira y Patricio Melero) ${ }^{31}$. Pese a esta formalización política, el gremialismo mantuvo en la UC su línea discursiva apartidista y con eje en la estructura universitaria del Movimiento Gremialista, órgano que luego de años de derrotas frente a la oposición, logró volver a presidir la FEUC a fines de la dictadura. En el ámbito popular urbano la UDI también incursionó desde el mismo año 83, logrando armar su Departamento Poblacional en algunas comunas y mediante un trabajo cercano con los alcaldes designados de la dictadura. Otras fuerzas oficialistas comenzaron el mismo proceso hasta que, luego del frustrado intento de configurar un solo gran partido de la derecha (el proyecto inicial de Renovación Nacional, que incluía a la UDI), en 1988 quedaron configurados los dos partidos que concentran el mayor peso del sector en la actualidad: la UDI y Renovación Nacional.

Los debates y orientaciones, tanto del movimiento estudiantil opositor como del activismo juvenil poblacional antidictatorial, apuntaban a la configuración general del orden social, en este caso, marcado por la dicotomía democracia - dictadura, considerándose que no había una problemática específica de la universidad, el liceo o la población que fuese ajena a los grandes temas político nacionales. Esta politización se acompañó de la conducción de los partidos políticos y la presencia masiva de militantes de partidos entre los activistas. El ciclo se cierra luego de que en 1988 Pinochet perdiera el plebiscito en que se decidía la aprobación o rechazo de su continuidad al mando del poder ejecutivo por ocho años más, y que un año más tarde ganara las elecciones el representante de la Concertación de Partidos por la Democracia, el demócrata cristiano Patricio Aylwin. Tras el nuevo gobierno se alinearon los partidos que fueron oposición a la dictadura con excepción del PC y un MIR ya fraccionado.

Este ciclo fue, en definitiva, de politización pública y visible de las expresiones juveniles organizadas. En el caso de la derecha, la venia oficialista les permitió formalizar partidos políticos, cuestión que les facilitó recomponerse tras las derrotas sufridas por el gremialismo en las elecciones de las federaciones ya democratizadas, y tras el retroceso de la intervención territorial de la dictadura ante la consolidación del tejido poblacional organizado. En el caso del centro y la izquierda, la militancia juvenil fortaleció sus orgánicas aprovechando una relativa apertura en que el régimen dejó funcionar algunos medios de comunicación opositores y toleró la presencia de dirigencias opositoras, particularmente las más moderadas que participaron de fallidos diálogos con el gobierno. Sin embargo, no se detuvo la represión ejercida desde estados de sitio, una férrea aplicación de los artículos transitorios y la constante apelación a un artículo octavo que prohibía las expresiones marxistas de la izquierda, lo que en la práctica

31 Ver: Víctor Muñoz Tamayo, Historia de la UDI. Generaciones e historia política 1973 - 2013, Santiago, Universidad Alberto Hurtado, 2016. 
significó que se mantuviera la censura, las detenciones, los relegamientos y los asesinatos que, aunque no tuvieron la intensidad de los primeros años, siguieron ejerciéndose como prácticas sistemáticas de terrorismo de Estado.

En este ciclo, los partidos opositores se consolidaron como conductores de los referentes de organización social y de las movilizaciones de protesta, tanto en el ámbito estudiantil como en el juvenil poblacional, de modo que la militancia partidista representó, en la práctica, un grado de compromiso mayor con la lucha anti-dictatorial. El fin de este ciclo tendrá que ver justamente con la crisis de tal posición y protagonismo de los partidos, en medio de una transición que dejó abierta la pregunta por la recomposición de la política institucional y su vínculo con lo social.

\section{Ciclo 4- Crisis de la politicidad social juvenil y politización a contracorriente $1990-2005$}

El movimiento estudiantil opositor de los años ochenta se politizó apuntando a la dicotomía democracia - dictadura. Esa dicotomía consideraba como dictadura a la integralidad de su obra refundacional, es decir, tanto su institucionalidad como el modelo económico-social construido. Sin embargo, la transición a la democracia mantuvo el modelo económico neoliberal y se hicieron limitados cambios a la Constitución de 1980, quedando vigentes una serie de aspectos que conservaban su espíritu autoritario (los llamados "enclaves autoritarios $^{*{ }^{* 3}}$ ), con las fuerzas armadas como garantes de la institucionalidad, y un parlamento que, por sistema electoral, tendía a la paridad de dos grandes bloques. De tal modo, la transición había sido estrictamente política (no socio económica) y muy limitada en ese aspecto. Quedaba la Constitución y un diseño institucional que tenía en sus objetivos la construcción de una sociedad despolitizada y un campo político tecnificado, elitizado, y con muchas trabas para tratar cuestiones estructurales que pudieran mermar la obra gruesa del modelo heredado.

El sistema político, en definitiva, se reconfiguraba formalmente pero se vaciaba socialmente, no sólo porque perdía militantes provenientes de frentes sociales, sino que además porque los sentidos de las conflictividades sociales no encontraban eco en ella, quedando básicamente como una disputa por la administración de un ordenamiento muy difícil de transformar, en donde la técnica y el discurso de la eficiencia desplazaban los cuestionamientos y valoraciones ideológicas que habían sido centrales en los ciclos anteriores. ${ }^{33}$

En ese contexto, el movimiento estudiantil universitario enfrentó una crisis que significó la desarticulación temporal de varias federaciones, entre ellas las de la Universidad de Chile y la Universidad de Santiago, dos de las principales universidades del país. ${ }^{34}$ Las causas son variadas, pero fundamentalmente se centran en el descontento y desencanto ocasionado por administraciones de directivas de federación adscritas a los partidos oficialistas, y la

\footnotetext{
32 Como la existencia de los "senadores designados" y "senadores vitalicios" (que incluyeron al propio Pinochet en 1998 en tanto ex presidente), la inamovilidad de las comandancias en jefe de las fuerzas armadas (que implicó tener al ex dictador dirigiendo el ejército hasta 1998) y las atribuciones y carácter del Consejo de Seguridad Nacional (y su influencia en la composición del Tribunal Constitucional).

33 Ver: Tomás Moulian, Chile actual. Anatomía de un mito, Santiago, Lom, 1997.

34 Thielemann, op cit, p $89-91$.
} 
ausencia de voluntad por retomar la agenda histórica de la democratización institucional y la superación del modelo de autofinanciamiento universitario. Por otro lado, las militancias cercanas a los sectores descontentos estaban profundamente dañadas por quedar excluidas del ordenamiento político posdictatorial (el PC quedaba aislado, con una crisis interna que significó la merma de su militancia universitaria y sin representación parlamentaria, el MIR se dividía, debilitaba y prácticamente desaparecía), y si bien surgían colectivos alternativos que desde la autonomía respecto de los partidos buscaban conducir la reactivación de un movimiento universitario democratizador y anti neo liberal, estos esfuerzos eran aún incipientes a inicios de la década del $90 .^{35}$

Con esta crisis, el movimiento universitario tocó fondo para rápidamente recuperarse mediante la activación de sus organizaciones tradicionales: las federaciones, pero esta vez, impulsadas por una red de militancias que iban más allá de los partidos políticos. Fue el tiempo de múltiples orgánicas denominadas "colectivos" y de una fuerte presencia de cuadros comunistas en las directivas. Tanto los colectivos emergentes como las Juventudes Comunistas -JJCC- tendieron a distinguir entre las militancias más acotadas y reducidas de sus núcleos, y un activismo asambleísta que convocaba a independientes simpatizantes de cada corriente. Eso ocurría, por ejemplo, en la Universidad de Chile, en donde coexistían asambleas dirigidas por colectivos emergentes como "La Surda" con la denominada "Asamblea de Estudiantes de Izquierda", instancia de activistas afines a la política de las JJCC.

De tal modo, hubo una izquierda que, aunque no contaba con presencia parlamentaria sí era protagonista de la recomposición de un campo sociopolítico en las universidades. Era un movimiento que reclamaba democratización en tanto participación de todos sus estamentos en los gobiernos universitarios, que se manifestaba crítico del sistema de autofinanciamiento universitario y se sentía agraviado por lo que se consideraba un desmantelamiento de la educación pública que no había sido frenado con la vuelta de la democracia. Desde esta crítica a la deriva del proceso transicional, se cuestionaba el orden social y se politizaba al movimiento, rechazándose la despolitización social que consagraba la Constitución de 1980. Era un movimiento que reivindicaba la lucha antidictatorial como algo que no había concluido pues, desde su perspectiva, la dicotomía democracia - dictadura adquiría una nueva dimensión: la herencia dictatorial aceptada en el marco de la nueva democracia instalada, versus una democracia imaginada que apelaba a sentidos de justicia social y que rechazaba el autofinanciamiento universitario y el neoliberalismo imperante. Por todo lo anterior, y dado el contexto de declive de los movimientos sociales en los años noventa, el movimiento universitario ha sido considerado una "anomalía" de politización. ${ }^{37}$

\footnotetext{
35 No está de más señalar que, en esta crisis de los movimientos estudiantiles y de los movimientos sociales en general, anidan causas estructurales vinculadas a las nuevas formas de ordenamiento de la sociedad chilena en el marco de un neoliberalismo avanzado. La nueva configuración de la estructura de clases, la introducción y ampliación creciente del financiamiento privado en la educación superior y escolar, entre otros elementos propios de la nueva matriz social chilena, constituyen aspectos que introdujeron dificultad a la mantención de las dinámicas colectivas propias del contexto histórico anterior. Sobre este tema, véase Carlos Ruiz y Giorgio Boccardo, Los chilenos bajo el neoliberalismo. Clases y conflicto social, Fundación Nodo XXI y Ediciones El Desconcierto, 2014.

36 Muñoz, op cit.

37 Thielemann, op cit.
} 
Esta politización estudiantil significaba un constante cuestionamiento del modelo, pero no una acción colectiva que pusiera en juego la reproducción del sistema de autofinaciamiento universitario y mucho menos del modelo económico en general. Las acciones del movimiento en la década fueron principalmente defensivas (detener privatizaciones de activos de la universidad, en algunos casos de modo exitoso y en otros sin éxito) y paliativas del constante déficit de los fondos de créditos necesarios para que los más pobres pudiesen estudiar mediante endeudamiento. Lo anterior hacía de las principales movilizaciones una cuestión repetitiva: cada año se otorgaban los créditos y los estudiantes se movilizaban acusando el déficit, ante lo cual el gobierno negociaba un nuevo monto. ${ }^{38}$ Paralelamente a ello, cada federación tenía una agenda de demandas puntuales relativas a la democratización, como aquella que echó a andar la Federación de Estudiantes de la Universidad de Chile FECH en 1997, mediante la cual conseguiría representación estudiantil en un Senado Universitario.

Durante este ciclo, en los estudiantes secundarios se da un repliegue del activismo con visibilidad pública, de modo que, si bien se termina el proceso de democratización de centros de alumnos, el impacto que estos tienen es fundamentalmente local. No es sino hasta el 2001 cuando irrumpe la protesta social de secundarios que se conoció como "mochilazo". Entonces, un agravio puntual movilizó a los estudiantes contra lo que se consideraba un alto pago por el "pase escolar", documento que otorga acceso a un precio rebajado al sistema de transporte público. Las instancias de organización de esa coyuntura fueron tremendamente novedosas y marcarían un giro trascendente en los estudiantes secundarios. No existiendo una estructura federativa de centros de alumnos, y debilitado el rol coordinador que habían tenido en el pasado las militancias partidistas, los estudiantes levantaron una organización asambleísta denominada Asamblea Coordinadora de Estudiantes Secundarios ACES, formada por representantes de cada colegio. Este referente se acompañó de un discurso que valoraba las relaciones horizontales entre los movilizados y la existencia de liderazgos en continua consulta a sus bases. Es decir, si bien la movilización tenía que ver con agravios y demandas puntuales, introducía cambios en la cultura política de la movilización secundaria y su modo de entender lo social frente a lo político y la política institucional, cuestión que irá a la par de un proceso de politización que ampliará los puntos de referencia de los agravios y los horizontes de la acción movilizada en la llamada "revolución pingüina" del año 2006. ${ }^{39}$

A nivel territorial, el activismo juvenil poblacional vivió como crisis el cambio de escenario que alteraba completamente lo que habían sido sus pilares de apoyo en el ciclo anterior. La militancia partidista, fundamental en las orgánicas juveniles poblacionales durante dictadura, fue profundamente mermada durante la transición, hubo desencanto en los sectores de la izquierda y también en el centro político respecto al carácter de la transición pactada y muchos dejaron de militar en sus respectivos partidos. La Iglesia Católica, asumiendo que la democracia debía abrir otros espacios para la libre participación social, transformó su vínculo con las organizaciones juveniles y dejó de dar la libertad temática y orgánica que había dado en los años ochenta, exigiendo objetivos puramente pastorales a quienes se organizaban a su

\footnotetext{
38 Moraga op cit.

39 "Pingüinos" se les denomina en Chile a los estudiantes de educación media, pues su uniforme consiste en un traje negro con una camisa blanca. Sobre este tema, véase Oscar Aguilera, Tamara Contreras, Sergio Guajardo, Raúl Zarzuri, La rebelión del coro. Análisis de las movilizaciones de los estudiantes secundarios, Santiago, documentos de trabajo CESC, 2006. Aguilera, op cit.
} 
alero. ${ }^{40}$ Por último, las ONG que habían sido importantes en la última parte de la dictadura en el apoyo a organizaciones, mutaron a ser órganos técnicos de ejecución de políticas públicas, o simplemente desaparecieron tras la retirada de los fondos de la solidaridad internacional.

Sin embargo, la crisis no rompió de modo permanente con los tejidos organizados de identidad juvenil, produciéndose un renacer de iniciativas que, como vuelta de un ciclo, nuevamente se orientaron por un eje artístico cultural. ${ }^{41}$ Fueron los años de centros culturales poblacionales, iniciativas de autoformación (preuniversitarios populares, por ejemplo) y redes que agrupaban a quienes expresaban sus percepciones sociales y descontento mediante determinadas estéticas, como fue el caso de las coordinaciones de hip hop poblacional. ${ }^{42}$ Varias de estas últimas iniciativas se conectaron con tipos de militancias, algunas antiguas, pero mayoritariamente nuevas, que se situaban por fuera de los circuitos más integrados de la política partidista.

Por su parte, la política partidista con inserción parlamentaria, salvo en los primeros años de la década de 1990, no tuvo como aspecto prioritario su inserción en organizaciones territoriales y federaciones estudiantiles al modo que lo había tenido en el ciclo anterior por parte de las fuerzas que fueron oposición a la dictadura. Hubo más bien un encapsulamiento de la militancia juvenil en sus estructuras internas, y una reducción de la masa militante al no contarse con el vínculo de antaño con los llamados "frentes sociales". Por su parte, la derecha partidista mantuvo expresiones marginales en las universidades, mientras el gremialismo conservó una presencia fuerte en la Universidad Católica, llegando a conducir la federación por varios años, y manteniendo un potente vínculo de cultura política en común con la UDI, aunque con separación orgánica de ella (nexo en gran medida administrado desde la fundación Jaime Guzmán). Lo anterior explica la razón de que la gran mayoría de los principales cuadros del gremialismo universitario pasaran a militar en la UDI una vez egresados. Otro aspecto relevante en relación a los partidos con inserción parlamentaria es que su militancia territorial giró en gran medida en torno a las actividades y labores de alcaldes y parlamentarios, llegando a asimilarse el rol de militante con el de trabajador o funcionario en tales espacios, o en dependencias del gobierno.

Una última coyuntura importante de este ciclo fue cuando, en el año 2005, las federaciones estudiantiles del país agrupadas en la Confederación de Estudiantes de Chile CONFECH, rechazaron la propuesta del gobierno de implementar un sistema de crédito bancario con aval del Estado CAE para alumnos de universidades privadas no pertenecientes al Consejo de Rectores (instancia que entonces agrupaba a las universidades tradicionales que recibían algún tipo de financiamiento estatal). A juicio de la $\mathrm{CONFECH}$, dado el permanente déficit de los fondos de crédito para las universidades tradicionales, el CAE podía terminar imponiéndose también en los centros dependientes del Consejo de Rectores, cuestión a todas luces negativa dado que sus intereses y condiciones de cobranza eran mucho peores que las del sistema de crédito ya existente en dichos centros. Tras intensas movilizaciones, los estudiantes

\footnotetext{
40 Myriam Olguín, "La organización juvenil en el espacio parroquial. Comunidad, protesta y éxodo en los 80", Proposiciones, Santiago, Sur, 1996.

41 Víctor Muñoz Tamayo, "Movimiento social juvenil y eje cultural. Dos contextos de reconstrucción organizativa. (1976-1982, 1989-2002)", Última Década 17, Viña del Mar, CIDPA, 2002, 41-64.

42 Raúl Zarzuri y Rodrigo Ganter, Culturas Juveniles, Narrativas Minoritarias y Estéticas del Descontento, Santiago, Ediciones UCSH, 2002. Pedro Poch, Del mensaje a la acción. Construyendo el movimiento Hip Hop en Chile (1984, 2004 y más allá), Santiago, Quinto Elemento, 2011.
} 
no fueron capaces de frenar el nuevo crédito, no obstante sectores de la CONFECH impulsaron un acuerdo con el Ministerio de Educación, MINEDUC, tendiente a establecer ciertos diques al avance del CAE respecto a los sectores más pobres del estudiantado de las universidades tradicionales. En ese marco, el acuerdo CONFECH MINEDUC estableció combinaciones de becas y créditos para cubrir los aranceles de referencia de los estudiantes de los quintiles más pobres (tres primeros quintiles), y crédito diferenciado según ingresos económicos de las familias hasta el cuarto quintil. ${ }^{43}$ La negociación dividió al movimiento, y las opiniones fueron desde aquellas que consideraron que la derrota había sido absoluta e insistieron en una demanda de arancel diferenciado, hasta las que valoraron el acuerdo como medida paliativa que al menos daba ciertas garantías en el sentido de evitar el CAE para los estudiantes más pobres entre los pertenecientes a las universidades del Consejo de Rectores.

En definitiva, la participación política juvenil durante este ciclo tiene dos elementos fundamentales: a) si bien los partidos no dejaron de tener presencia en las redes juveniles estudiantiles y territoriales, dicha presencia estaba lejos de tener la relevancia y predominancia de décadas anteriores; y b) surgían pequeñas expresiones militantes en los espacios estudiantiles, particularmente universitarios, los que se unían en redes que interpretaban de algún modo el vínculo político de lo social (los llamados "colectivos"), algunas de ellas identificadas con ciertas estructuras y tradiciones políticas no insertas en el sistema de partidos, muchas no partidistas o declaradamente autónomas respecto a orgánicas mayores, y todas ellas con pretensiones diferentes sobre el proyectarse o no a nivel nacional. ${ }^{44}$ Todo ello, como politización más bien defensiva ante la hegemonía neoliberal de las políticas sectoriales que involucraban a los estudiantes, con un discurso que proyectaba un largo plazo de reconstrucción de movimiento social, con demandas de alcance mediano que no tocaban el modelo en términos integrales, y con limitada o nula capacidad (también desinterés o rechazo) en relación a insertarse o incidir en un campo político institucionalizado y expresado en las instancias formales de la democracia representativa. La política propia del movimiento se vivenciaba preferentemente como política estudiantil ante adversarios estructurales e institucionalizados en el Estado y el sistema político formal, y era básicamente vista como un campo en reconstrucción. El ciclo termina cuando, desde el movimiento estudiantil, el alcance de las demandas va a dar saltos cualitativos hacia ejes estructurales del modelo, lo que desplazará los horizontes de la política propia hacia interpelaciones a actores nacionales más allá de lo educativo, es decir, se hablará con más énfasis a la sociedad en su conjunto, y varias orgánicas de la política estudiantil buscarán alternativas de incidencia en una política nacional.

\section{Ciclo 5- Politización ascendente, interpelación a la sociedad y disputa por la política. 2006-2011}

Uno de los sellos que marcó el contexto político-electoral del año 2005 y la posterior victoria de la Presidenta Bachelet fue el debate en torno a la necesidad de profundizar el carácter participativo y ciudadano de un sistema democrático afectado por un acelerado

\footnotetext{
43 Ver documento: Acuerdo CONFECH - MINEDUC, Santiago, 13 de septiembre de 2005, firmado por el ministro de educación Sergio Bitar y los representantes de CONFECH. En www.mineduc.cl

44 Katia Valenzuela, “Colectivos juveniles: ¿inmadurez política o afirmación de otras políticas posibles?”, Última Década 26, Valparaíso, CIDPA, 2007, 31-52.
} 
proceso de rutinización. En un contexto marcado por la progresiva elitización de la práctica política, la desafección ciudadana y la predominancia de dirigencias políticas que progresivamente iban perdiendo su potencia interpelatoria, la incorporación de una propuesta política sintetizada en la promesa bacheletista de un "gobierno ciudadano" generaba expectativas y abría una ventana de oportunidad para la puesta en discusión de una agenda de refortalecimiento democrático. ${ }^{45}$

Con el telón de fondo de este nuevo clima social y político en el país es que, a pocos meses del inicio de la nueva administración, los estudiantes secundarios irrumpen con fuerte visibilidad en la escena pública protagonizando una masiva movilización social que incluyó la ocupación de decenas de establecimientos educacionales y la realización de movilizaciones masivas a lo largo de todo el país. Esta coyuntura de visibilización de la movilización estudiantil, conocida como "la revolución pingüina",46, constituye una consecuencia visible del proceso de rearme lento y progresivo de la organización estudiantil descrito en el apartado anterior, y expresa un punto de inflexión en lo que refiere a la capacidad de las organizaciones juveniles para exponerse en la escena pública, alterando la agenda política y logrando niveles de incidencia difícilmente identificables en los períodos inmediatamente anteriores.

En un comienzo, las movilizaciones siguieron la dinámica de presentación de demandas puntuales y corporativas tales como la exigencia de gratuidad en el pase escolar y en la Prueba de Selección Universitaria, además de modificaciones en la gestión de la tarifa escolar de la locomoción colectiva y un conjunto de demandas asociadas a las endémicas carencias a nivel infraestructural de los establecimientos de educación pública y subvencionada. Sin embargo, la inicialmente heterogénea acumulación de demandas locales fue confluyendo progresivamente en un reclamo general de mejora de la educación pública y en una crítica política a las bases institucionales de la educación y su sello de mercado otorgado por el modelo neoliberal. Los déficits detectados en el cúmulo de petitorios locales levantados por estudiantes de diversas localidades del país, así, iban traduciéndose progresivamente en la demanda común por poner término al ordenamiento municipal del sistema escolar chileno.

Es así como, en definitiva, el conjunto de demandas que movilizaron las energías estudiantiles durante los primeros meses del año 2006 culminaron materializándose en una exigencia que conformó el leit motiv de la movilización pingüina: la derogación de la Ley Orgánica Constitucional de Enseñanza que establecía las normas que rigen el sistema educacional chileno, en el marco de un modelo en que el Estado cumple un rol subsidiario respecto al mercado. Una demanda que, a todas luces, operaba como cristalización del cuestionamiento estudiantil al modelo de educación más que a aspectos puntuales del mismo.

Con el correr de los días, el tenor de las movilizaciones estudiantiles se elevó rápidamente a tema nacional. Abruptamente, su intensidad fue en aumento, "recibiendo como respuesta gubernamental una ambigua solidaridad y "comprensión" combinada con el

\footnotetext{
45 Sobre el efecto político del acceso de Bachelet al gobierno en el año 2006, véase Mauricio Morales, "La primera mujer Presidenta de Chile. ¿Qué explicó el triunfo de Michelle Bachelet en las elecciones de 2005-2006", Latin American Research Review, 43: 1, 2008, 7-31; Patricio Navia y José Izquierdo, "Cambio y continuidad en la elección de Bachelet”, América Latina Hoy 46, Salamanca, Universidad de Salamanca, 2007, 75-96.

46 Para un análisis sumario del fenómeno de la "revolución pinguina" véase Juan Eduardo García Huidobro, “¿Qué nos dejó la movilización de los pingüinos?”, Nomadías 9, Santiago, Universidad de Chile, 2009, $205-207$. Un análisis detallado, que incorpora la descripción de este acontecimiento con la trayectoria histórica de las movilizaciones estudiantiles en Oscar Aguilera, op. cit.
} 
categórico cuestionamiento a sus formas -marcadas por fuertes dosis de violencia y desorden callejero, en un intento por apuntalar la autoridad presidencial desde el inicio y subrayar la imagen de un gobierno serio que no alteraba su hoja de ruta por temor al descontento social" 47 . Contrariamente a las intenciones gubernamentales, sin embargo, el cuestionamiento de las formas de la protesta estudiantil trajo como consecuencia su intensificación al mismo tiempo que el surgimiento de nuevas estrategias de movilización que extendieron el conflicto hasta que la Presidenta Bachelet anunció, en una cadena nacional que daba cuenta de la relevancia que había adquirido el conflicto, una serie de medidas inmediatas acompañadas de la convocatoria a un Consejo Asesor Presidencial cuyo objetivo debía centrarse en la discusión y elaboración de propuestas para una reforma integral en el ámbito de la educación. Para integrar dicha comisión, el gobierno convocaba a representantes de distintos estamentos del mundo educacional, expertos e investigadores, representantes del mundo político y dirigentes estudiantiles del mundo secundario y universitario.

Por primera vez desde el retorno a la democracia, el movimiento estudiantil lograba de este modo la conformación de un espacio potencialmente incidente de discusión en torno a las bases del sistema educacional chileno. Los debates de fondo acerca del rol del Estado, el lugar del mercado y la centralidad de la educación en el modelo económico-social ingresaban en la primera línea de la agenda pública, expresando de este modo la capacidad de los estudiantes secundarios -inédita desde sus luchas contra la municipalización durante la década de los ochenta- para trascender la disputa corporativa y articular sus demandas con una tematización de las bases mismas del modelo económico-social chileno.

Pese a lo anterior, el anuncio de conformación del consejo -en el que los estudiantes iban a tener una representación parcial de acuerdo al diseño del ejecutivo- no estuvo exento de debates al interior del movimiento estudiantil, tensionado por la dicotomía entre continuar las movilizaciones y obviar su incorporación a la instancia oficial, o bien reemplazar su presión callejera por la participación en el Consejo. Finalmente, y no sin fuertes tensionamientos internos, los estudiantes optaron por incorporarse al Consejo, el que comenzó sus funciones durante el mes de junio con una duración total de 27 semanas. Las movilizaciones, como resultado de ello, fueron en progresivo decaimiento, manifestando al mismo tiempo algunas fracturas al interior del heterogéneo conjunto de organizaciones estudiantiles.

Como resultado de sus encuentros, el Consejo concluyó sus funciones elaborando dos documentos: "un informe preliminar destinado a la elaboración de un diagnóstico del estado del sistema educacional chileno, y un Informe final con observaciones y recomendaciones para una reforma educacional integral que, a falta de acuerdo entre sus miembros, se elaboró como un agregado de recomendaciones y criterios, algunos de los cuales resultaban fuertemente contradictorios entre sí" 48 .

La deriva posterior del procesamiento gubernamental del conflicto estudiantil, sin embargo, se dirigiría por un camino contrario a las aspiraciones pingüinas. Si bien las movilizaciones generaron respuestas satisfactorias en algunas demandas puntuales y generaron un espacio para la discusión de los problemas de fondo de la educación chilena, los resultados generados a partir de la convocatoria gubernamental al Consejo Asesor no fueron

47 Carlos Durán, “Campo político-institucional y procesamiento del malestar social en Chile, 1999-2009”, Izquierdas 40, Santiago, USACH IDEA, 2018: 18.

48 Ibid., 20. 
satisfactorios para los estudiantes. Ocurrió que, a contrapelo del largo debate del organismo asesor, un acuerdo de los jefes de todos los partidos con representación parlamentaria fue el que dio finalmente forma a la nueva ley de educación que luego sería aprobada por el parlamento. Un acuerdo que, ceremonias mediante, tuvo como grandes ausentes justamente a los estudiantes.

Pero la derrota estudiantil en lo que refiere a su nivel de incidencia en la reforma educacional gestionada por Bachelet también estuvo acompañada de un conjunto de hechos relevantes para la comprensión de la deriva posterior del movimiento estudiantil chileno. Y ello, por cuanto las movilizaciones enmarcadas en la "revolución pingüina" fueron la expresión de un proceso de progresiva politización de las demandas estudiantiles, que manifestaron la capacidad de articularse en torno a un discurso de impugnación del modelo educacional más que de sumatoria de reivindicaciones particulares y corporativas. El desarrollo de nuevas experiencias de organización estudiantil en torno a "colectivos" con una fuerte vocación asambleísta, junto a la incorporación de cientos de jóvenes a organizaciones políticas de diverso tipo (incluyendo incluso algunas partícipes del campo político-institucional), expresaron por otro lado una capacidad de constitución de espacios de acción altamente eficientes en cuanto a sus objetivos movilizadores, constructores además de una conciencia organizacional y politizada que, algunos años después, generará efectos de amplia relevancia para el proceso político chileno. ${ }^{49}$

Los años inmediatamente posteriores a la revolución pingüina fueron tiempos de repliegue de las movilizaciones estudiantiles. Los amplios costos pagados por los estudiantes secundarios generaron un efecto de inmovilización y de erosión de las múltiples identidades socio-políticas constituidas en este espacio, afectado como ya lo señalamos por los modestos resultados alcanzados a nivel legislativo.

Pero este estado de repliegue del mundo estudiantil comenzaría a cambiar abruptamente algunos años después. Antes de ello, el año 2010 asumía la presidencia de la República Sebastián Piñera, y por primera vez desde el retorno de la democracia, se instalaba un gobierno de derecha que parecía consolidar las bases del modelo económico-social chileno, y cerrar por consecuencia las puertas a modificaciones relevantes en el ámbito educacional.

Luego de un primer año tranquilo para la nueva administración derechista, año marcado por la reconstrucción post-terremoto y el mundialmente conocido evento del rescate de los mineros de Atacama, la irrupción de movilizaciones territoriales y medioambientales comenzaba a dar luces de un escenario complejo, el que terminaría por expresarse con toda su intensidad desde mayo del año 2011, cuando las movilizaciones estudiantiles -esta vez conducidas desde el sector universitario- coparían la agenda política del país durante meses.

$\mathrm{Si}$ bien estas movilizaciones manifestaban una relación de continuidad con las demandas estudiantiles del contexto post-dictatorial, (se volvía a rechazar el autofinanciamiento de las universidades, el endeudamiento al que se sometía a los estudiantes universitarios, así como el rol determinante del mercado y del lucro en el sistema educativo en general), su alcance mostró rápidamente una sustantiva diferencia cualitativa. Y es que,

\footnotetext{
${ }^{49}$ Respecto al vínculo entre las dinámicas asamblearias y las orgánicas políticas que, sin dudas, tuvieron una fuerte presencia durante este período en el mundo estudiantil, consideramos que no es possible establecer una oposición binaria entre ellas. Por el contrario, las fronteras que separan a los "colectivos" de las "organizaciones políticas" son porosas y cuentan con diversos puntos de intersección.
} 
mientras en lo que respecta al financiamiento de la educación superior los movimientos estudiantiles de los noventa y del dos mil demandaron volver al sistema de arancel diferenciado e incrementar las becas para los grupos más vulnerables, este movimiento surgido el 2011 fue explícito en sostener que "lo justo" era que el Estado garantizara una educación pública, gratuita y de calidad. Lo anterior evidenciaba que, esta vez, el movimiento no sólo pedía reformas puntuales al sistema universitario, sino que exigía una política conducente al término del modelo educativo de mercado con todas sus implicancias de desigualdad y endeudamiento. Una demanda que, bajo la consigna de "No al lucro", logró interpelar a amplios sectores de la sociedad chilena que adhirieron - con mayor o menor proactividad- a las masivas, creativas y persistentes manifestaciones estudiantiles que caracterizaron todo el año 2011.

En sus movilizaciones, tanto los universitarios como los estudiantes secundarios rechazaron el lucro en la educación, denunciaron el modelo vigente como "apartheid educacional" y exigieron que el Estado garantizara gratuidad a fin de que la calidad de la educación recibida no fuese mediada por la condición socioeconómica del estudiante. Los estudiantes secundarios enfatizaron en una crítica a la realidad segmentada y segregada del sistema escolar, lo que relacionaban con un diagnóstico de crisis de la educación pública administrada por los municipios y una percepción negativa de los efectos del lucro en la educación particular y particular subvencionada.

El protagonismo juvenil en este ciclo fue fundamentalmente un protagonismo estudiantil, entre otras cosas, porque una identidad fundada en una condición estructural como la de ser estudiante fue el lugar desde donde se cuestionó la estructura y la integralidad del modelo heredado de la dictadura, proyectando demandas que avanzaron a proponer una readecuación de los vínculos entre Estado, mercado y sociedad, es decir, destinadas a alterar la cara institucional y económica del orden posdictatorial. Lo anterior no impidió, por cierto, que un amplio abanico de identidades culturales juveniles así como formas novedosas de vinculación virtual desembocaran en este y otros movimientos dando variedad a las expresiones de la protesta y a la lucha por instalar las valoraciones y lecturas políticas del movimiento, lo que a la vez diversificó notablemente el rol y carácter de los activismos y liderazgos. ${ }^{50}$

Las circunstancias que condujeron a los estudiantes secundarios y universitarios a protagonizar la mayor expresión de protesta social desde la década de los ochenta son múltiples y responden a factores diversos que trascienden los objetivos de este trabajo. Sin embargo, lo que constituye un hecho indesmentible es que, durante los meses de protagonismo estudiantil, sus demandas lograron no solo trascender su interés corporativo, sino que además producir una potente interpelación a la sociedad chilena, incorporar a miles de jóvenes a una nueva identidad socio-política dotada de objetivos claros, una estética potente y un discurso político impugnatorio al modelo económico-social chileno. La potencia expresada en las movilizaciones, así, concluyó en la activación de una crisis política y social inédita desde el retorno a la democracia. Una crisis que, sin dudas, emergió desde los núcleos de un mundo

\footnotetext{
${ }^{50}$ Ver: Camila Ponce, De los libros a la calle: La transformación cultural y politica de los jóvenes militantes chilenos a partir de las movilizaciones estudiantiles de 2011, tesis doctoral, École doctorale de l'EHESS, París, 2017.
} 
estudiantil que, tras dos décadas de una difícil capacidad de incidencia en la deriva del proceso socio-político, se constituyeron en protagonistas indiscutibles. ${ }^{51}$

Esta vez, el ciclo se cerraba porque el movimiento juvenil había logrado romper el sentido común de una política tecnificada, una sociedad despolitizada y una participación social limitada al alcance de los particularismos de cada gremio o sector de la sociedad. El movimiento estudiantil declaró hablarle a toda la sociedad y por toda la sociedad, apuntando a transformaciones integrales y estructurales, exigiendo vinculaciones entre actores e incidencia en la construcción del orden social. Se politizaba al tiempo que se disputaba el sentido de lo que debía ser la política. Agotadas las lógicas sociopolíticas características de la posdictadura, este ciclo terminaba porque el propio movimiento debía generar nuevas lógicas y formas para enfrentar nuevos desafíos propios del nuevo escenario que había colaborado decisivamente a generar.

\section{Ciclo 6.- De la política de los campus a la política nacional. Repartidización y reconfiguración del campo político, 2011-2017}

La irrupción durante el año 2011 del mayor ciclo de movilizaciones sociales desde el retorno a la democracia se gestó en un contexto que, paradojalmente, parecía anunciar la consolidación del modelo político, económico y social construido por la dictadura. La victoria del candidato derechista Sebastián Piñera en las presidenciales del año 2009/2010, sumado a la profunda crisis de la Concertación y la concentración del debate público en el tema de la eficiencia en la gestión gubernamental, anticipaban hacia inicios del año 2010 la reconfiguración del campo político en la dirección del avance hegemónico de una derecha que parecía haber superado la herencia autoritaria y se instalaba como un actor capaz de capitalizar eficientemente el desgaste de un conglomerado político que había cumplido casi 20 años en el gobierno.

Contrario a ello, y tal como se expuso anteriormente, la aparente dirección que el proceso socio-político chileno asumía con la victoria de Piñera giró abruptamente hacia la activación de un ciclo de movilizaciones inédito que, junto con sus efectos contenciosos, fue capaz de alterar la gramática política del país. Y es que, en efecto, la amplia agenda de movilizaciones territoriales, ambientales y estudiantiles activadas desde finales del año 2010 generó como consecuencia la incorporación de nuevos temas en la agenda política nacional, entre los cuales destacó la cuestión de la desigual distribución territorial de los beneficios y las cargas sociales, la demanda por derechos sociales por fuera del mercado, el cuestionamiento de la legitimidad del orden constitucional y el debate en torno a la justicia tributaria.

Abruptamente entonces, en amplios sectores de la sociedad chilena el eje del debate público giró desde la centralidad de la eficiencia como valor incuestionable a la tematización de demandas, diagnósticos y propuestas de reforma hasta ese entonces fuera del espacio de discusión del campo político-institucional. Axiomas hasta ese momento naturalizados pasaron a constituirse en materia de debate público, y actores otrora arrinconados en el locus de la

51 En relación a las dinámicas políticas generadas al interior del movimiento estudiantil del año 2011, véase Octavio Avendaño, "Fracturas y representación política en el movimiento estudiantil: Chile 2011", Última década 41, Valparaíso, CIDPA, 2014, 41-68. 
demanda sectorial derivaban en agentes con capacidad de interactuar agonalmente con los actores político-institucionales.

Pues bien, dentro de estos nuevos agentes del debate público nacional se encontraba el mundo estudiantil, protagonista de las movilizaciones que durante el año 2011 -y tal como ya fue expuesto- pusieron en jaque al gobierno de Piñera, interrumpiendo su agenda e instalando en el centro de la discusión pública la demanda por una educación "pública, gratuita y de calidad".

Configurado en torno a una diversidad de organizaciones y colectivos vinculados de modo heterogéneo con lo político y con grados diferenciados de formalización, este mundo presentaba como común denominador el estar conformado esencialmente por activistas, liderazgos y estilos de expresión de tipo juvenil. ${ }^{52} \mathrm{~A}$ diferencia del resto de las expresiones de protesta social desplegadas en este ciclo, las movilizaciones emergidas desde el mundo estudiantil se caracterizaron entonces por su homogeneidad etaria, cuestión que naturalmente generó efectos relevantes en cuanto a la utilización de recursos innovadores que alteraron de modo significativo los patrones de la acción colectiva contenciosa característicos hasta entonces. A las tradicionales paralizaciones, "tomas" de instituciones educativas, marchas y protestas, los estudiantes sumaron un conjunto diverso y creativo de recursos tales como la irrupción en espacios públicos (red pública del metro y transporte público en general, centros comerciales, instituciones gubernamentales, etc.) y la realización de eventos de alto impacto público y creatividad ("besatones", "maratones por la educación" y performances de diverso tipo) que aportaron de modo significativo a la visibilización pública de sus demandas y la mantención de la intensidad y poder de convocatoria de las movilizaciones ${ }^{53}$

Naturalmente las formas, impacto y dinámica que asumieron las movilizaciones estudiantiles no pueden ser explicadas en función exclusiva de la configuración etaria de sus protagonistas, sino que más bien atendiendo en primer lugar a sus condicionantes generacionales. En su gran mayoría, los participantes y líderes de la así llamada "Primavera de Chile" eran jóvenes que, situados etariamente entre los 15 y los 25 años, accedieron a sus procesos de socialización política en un contexto 1) alejado de las tensiones del período posttransicional, 2) con la figura de Pinochet fuera de la agenda pública y 3) con un campo políticoinstitucional rutinizado y carente de la cohesión discursiva propia de la década anterior. Para esta generación, la retórica de los consensos, la valoración axiomática del modelo económicosocial y la auto-restricción de las demandas sectoriales constituían elementos ajenos a su marco experiencial público. Y ello se expresaba claramente en el contenido de sus demandas, los repertorios utilizados y las prácticas organizativas que caracterizaron su accionar.

Tales modificaciones, en definitiva, derivaron en la activación de una forma de acción política sustancialmente distintas a las configuradas por la gramática postransicional. Frente a las formas "politizadas" del campo político-institucional hegemónico, las movilizaciones estudiantiles operaron en los términos de lo que Flisfisch definía -haciendo referencia a las formas de politización en tiempos autoritarios- como una "política que politiza", vale decir,

52 Ver Marcelo Mella, "Composición, correlaciones de fuerza y elaboración de estrategias en el Pleno CONFECH (2011- 2015)", Última década 45, Valparaíso, CIDPA, 2016, 75-92.

53 Sobre los repertorios utilizados en las movilizaciones estudiantiles del 2011, véase Juan Pablo Paredes, $L a$ educación cbilena no se vende ise defiende! La política de significación de la movilización por la Educación Pública en Chile. 20112013, Tesis para optar al Grado de Doctor en Ciencias Sociales, Santiago, Facultad de ciencias sociales, Universidad de Chile, 2015. 
una forma de intervención política que en su facticidad altera los términos, los contenidos y las formas de la política instituida.

La intensidad de las movilizaciones estudiantiles del año 2011, unida a las expresiones contenciosas desplegadas en el campo de las luchas ambientales o territoriales, fueron por consecuencia un factor clave a la hora de comprender lo que el PNUD, en su Informe de desarrollo humano en Chile del año 2015, caracterizó como un "tiempo de politización" caracterizado por "la ampliación de la discusión pública, (...) el aumento de la conflictividad y la movilización social, (y) el involucramiento ciudadano". ${ }^{54}$

Pero las dinámicas propias de la acción colectiva inexorablemente se ven enfrentadas a ciclos de emergencia y repliegue. Ya desde finales del año 2011, la intensidad de las movilizaciones estudiantiles abrió paso a un período de rutinización, y la característica cohesión de sus estrategias de visibilización se vio enfrentada al surgimiento de agendas particulares y divisiones táctico-estratégicas que fueron generando una progresiva recuperación del control de la agenda pública por parte de los actores político-institucionales. El destino del movimiento estudiantil y de los agentes que protagonizaron la irrupción del año 2011 comenzaba a verse enfrentado a la deriva convencional de las movilizaciones sociales: un período de visibilidad seguido de un repliegue hacia la interioridad de los espacios identitarios y corporativos.

Y sin embargo, el transcurrir de las organizaciones estudiantiles protagonistas del ciclo 2011 generó una trayectoria distinta. Tras un breve período de repliegue, muchas de las organizaciones y liderazgos surgidos y/o fortalecidos durante este ciclo de movilizaciones sociales comienzan a gestar un proceso lento y progresivo de inserción en el espacio políticoinstitucional. Un proceso que, inédito desde el fin de la dictadura militar, condujo a que la repolitización arriba referida fuera acompañada de un proceso de partidización consistente en la voluntad de disputar en los espacios político-institucionales, ampliando el alcance de las demandas estudiantiles y disponiéndose a utilizar y/o crear instrumentos para la participación plena en el campo político-institucional.

Ilustraciones ejemplares de este proceso pueden verse expuestas en el caso de los tres liderazgos principales del ciclo de movilizaciones estudiantiles: Camila Vallejo, Giorgio Jackson y Gabriel Boric ${ }^{55}$. Capitalizando sus respectivos liderazgos construidos al calor de las movilizaciones estudiantiles, estos tres dirigentes universitarios compitieron exitosamente en

\footnotetext{
54 PNUD, Desarrollo bumano en Chile. Los tiempos de la politización, Programa de Naciones Unidas para el desarrollo, Santiago, 2015, p. 15.

55 Camila Vallejo (2011) y Gabriel Boric (2012) se desempeñaron como presidentes de la Federación de estudiantes de la Universidad de Chile (FECH). Giorgio Jackson, por su parte, fue el máximo representante de la Federación de estudiantes de la Universidad Católica (FEUC) durante el año 2011. Estos casos no solo resultan ejemplares por la relevancia de los dirigentes en cuestión, sino que además por la diversidad de sus respectivos espacios políticos. En el caso de Jackson y Boric, ambos dirigentes formaron parte de orgánicas políticas (el primero de Revolución Democrática que se fundó el 2012, el segundo de Izquierda Autónoma que era heredera de agrupaciones de izquierda estudiantil como la Zurda de los años 90) que, si bien compartían el domicilio político de la izquierda extra-concertación, discrepaban en ese entonces del sentido estratégico atribuido a su accionar político. En el caso de Camila Vallejo, su condición de militante comunista la ubicó como parte del conglomerado Nueva Mayoría del cual dicho partido comenzó a formar parte desde 2013.
} 
las elecciones parlamentarias del año 2013, obteniendo un escaño parlamentario y participando de modo protagónico en el debate político nacional. ${ }^{56}$

Naturalmente, la llegada al parlamento de los principales líderes estudiantiles del ciclo de movilizaciones arriba referido no fue una expresión episódica de incorporación de actores políticos outsiders, sino que más bien síntoma de un proceso de repartidización que se tradujo en el surgimiento de nuevas organizaciones políticas, en algunos casos, y en el relevamiento de los liderazgos, estilos y tópicos juveniles, en otros. Desde la izquierda externa a la Nueva Mayoría emergieron agrupaciones con pretensiones de inserción parlamentaria como Revolución Democrática (2012), Izquierda Libertaria (2015) y Nueva Democracia (2016); mientras nuevas divisiones de agrupaciones autonomistas herederas de La Surda terminaron dando lugar a un sector que mantuvo el nombre Izquierda Autónoma y a otro que pasó a denominarse Movimiento Autonomista (2015). Todas estas agrupaciones tienen una historia que hunde sus raíces en la izquierda universitaria de la posdictadura, reivindicando diferentes tradiciones, perspectivas ideológicas y valoraciones de aprendizaje político que han sedimentado una cultura militante en constante transformación. Por lo mismo, en sus procesos de partidización terminaron convocando a los herederos identitarios de esa historia mayor, logrando articular referentes de una composición etaria que trascendió la juventud universitaria. En la izquierda de la Nueva Mayoría también ocurrieron fenómenos originados en las rupturas del 2011, como una reconfiguración de corrientes internas del PS en donde nuevas generaciones promovieron políticas en base a lecturas generacionales ${ }^{57}$, o en el caso del PC, una clara renovación de cuadros y un notable empoderamiento de las Juventudes Comunistas a nivel de la estructura partidaria nacional. ${ }^{58} \mathrm{La}$ derecha por su parte, mostró a un movimiento gremial que reaccionó redefiniendo su discurso de apoliticismo e iniciando una oposición activa y explícita al gobierno de Bachelet, cuestión que no había hecho con anteriores gobiernos de la Concertación de Partidos por la Democracia. Es importante dejar en claro que no toda la izquierda acepta un camino de partidización con presencia en el sistema

\footnotetext{
${ }^{56} \mathrm{La}$ incorporación de dirigentes estudiantiles al terreno político-institucional no se redujo naturalmente a los ya mencionados. Existen otros casos de dirigentes estudiantiles que participaron en la disputa parlamentaria (Carol Cariola, dirigente comunista de la Universidad de Concepción, y Francisco Figueroa, dirigente de Izquierda Autónoma en la Universidad de Chile, la primera electa, no así el segundo) o que, una vez asumido el mandato de la Presidenta Bachelet el año 2014, asumieron cargos de gobierno (caso de Camilo Ballesteros, Presidente de la Federación de Estudiantes de la Universidad de Santiago FEUSACH durante el 2011).

57 Víctor Muñoz Tamayo, "El Partido Socialista de Chile y la presente cultura de facciones. Un enfoque histórico generacional (1973 - 2015)", Iqquierdas, número 26. USACH - IDEA, Santiago, 2016.

${ }^{58}$ En relación al movimiento estudiantil,universitario, se debe mencionar que las JJCC son la única estructura de militancia que permanece con protagonismo en todos los ciclos analizados, aunque no por ello dejando de vivir situaciones de crisis. Tras el golpe de Estado, la represión a los comunistas es fuerte, pero se mantienen estructuras militantes que permiten su presencia en la conducción de organizaciones de activismo cultural como la ACU. En los años ochenta, la masividad de su militancia en los campus sólo se puede igualar al de la Juventud Demócrata Cristiana, y si bien en el inicio de los años 90 vive una crisis profunda, se levantó como una de las fuerzas que estuvieron a la cabeza de la politización estudiantil en transición. Durante el 2011, es sabido que buena parte de las federaciones estuvieron encabezadas por dirigentes comunistas. Para un mayor detalle: Muñoz op cit. Luis Thielemann, "Hijos de Recabarren, hijos de la transición:sobre las JJCC y la anomalía estudiantil de los 90”, Rolando Álvarez y Manuel Loyola, Un trébol de cuatro hojas. Las juventudes comunistas de Chile en el siglo XX, Santiago, Ariadna, 2014. Fernando Pairicán, "La gran crisis: las Juventudes Comunistas de Chile defendiendo su identidad en tiempos de transición y renovación democrática 1989 - 1992”, Izquierdas 30, Santiago, USACH IDEA, 2016, 124 - 160.
} 
político, y en el movimiento estudiantil, sobre todo en el movimiento secundario, algunas coordinaciones, como la ACES, promovieron un activismo anti partidos y anti elecciones, rechazando las posturas que iban en dirección contraria y acusándolas de traicionar la independencia del movimiento social.

Superando la larga tradición de luchas corporativas y sectoriales desarrolladas por el mundo estudiantil desde el fin de la dictadura militar, la deriva de las movilizaciones del año 2011 condujo en definitiva a la incorporación de una porción relevante de ese mundo en la disputa política nacional. ¿Cuáles son los motivos que explican esta trayectoria? A nuestro juicio, este proceso de partidización de las identidades juveniles vinculadas al mundo estudiantil se asocia a tres fenómenos que concurren sincrónicamente:

a) A nivel macro-político, la crisis del gobierno de Piñera, unida al posterior surgimiento de una nueva coalición de centro-izquierda -la Nueva Mayoría- que alcanza el poder bajo el liderazgo de Michelle Bachelet (2013), produce un clima político afín a la activación de una agenda de corte reformista que parcialmente acogía el sentido de las demandas estudiantiles del año 2011. El posterior fracaso del gobierno de la Nueva Mayoría en cuanto a conducir un proceso de reformas capaz de contar con el respaldo de la mayoría social y política del país produjo finalmente una ventana de oportunidad que, vinculada con cambios en la legislación electoral, fue cubierta desde el mundo de las organizaciones políticas vinculadas al proceso de movilizaciones del 2011.

b) La fuerte capacidad de intervención en la agenda pública por parte de las organizaciones estudiantiles y de sus líderes, unido a su habilidad para descorporativizar su retórica y producir sentido y adhesión en las mayorías ciudadanas generaron una doble consecuencia: por una parte, quedó en evidencia que la potencia interpelatoria del discurso transformador encarnado en el mundo estudiantil era efectiva pero, por otro lado, también quedó claro que dicha potencia tenía en la lógica político-institucional un límite infranqueable, primero representado en la administración Piñera y luego en la forma en que el gobierno de Bachelet administró el proceso de reforma educacional. Todo ello generaba valiosos argumentos como para reconocer la necesidad de abandonar el corporativismo, superar el internismo y construir una agenda partidaria de incorporación y disputa en el campo político-institucional.

c) La extensión de las movilizaciones estudiantiles durante más de un año fue generando un espacio de socialización del variopinto mundo de la izquierda estudiantil que se tradujo en la gestación de redes, sentidos comunes y un discurso compartido que, con el correr del tiempo, fue un factor clave en la afectación de los tradicionales particularismos y sectarismos propios de la cultura política estudiantil.

La articulación de estos factores fue generando en el heterogéneo mundo de las organizaciones juveniles y estudiantiles protagonistas de las movilizaciones del 2011, en definitiva, la certeza respecto a la necesidad del paso a la disputa política como eje de su accionar colectivo. Dicha certeza, complementada con un contexto socio-político que generó la oportunidad de la emergencia hacia la política-institucional, es la que se expresó de un modo ejemplar durante el año 2017 en la conformación del conglomerado Frente Amplio y su exitosa participación en la disputa electoral del mismo año. Una disputa que, a la luz de sus 
resultados, permitió lo que por ahora puede ser asumido como una incorporación definitiva de estos mundos a la disputa político-institucional. ${ }^{59}$

En definitiva, la emergencia del movimiento estudiantil en tanto actor protagónico en la disputa política-hegemónica nacional derivó posteriormente en un progresivo proceso de articulación que concluyó en una expresión política emancipada de las luchas corporativas que caracterizaron al movimiento estudiantil durante más de dos décadas. La fuerte irrupción del año 2011, así, lejos de conducir a los recurrentes ciclos de repliegue del movimiento estudiantil, condujo esta vez a un inédito proceso de partidización e incorporación a la política institucional. Un proceso paulatino, no exento de tensiones y cuyo destino aún está por definirse.

\section{Conclusiones}

En este artículo nos hemos propuesto exponer un criterio de periodización de la deriva histórica de los movimientos estudiantil-juveniles chilenos desde la década de los sesenta y hasta la actualidad. ${ }^{60}$ Específicamente, hemos argumentado en torno a la determinación de seis grandes etapas posibles de establecer como criterios de análisis de la historicidad de dicha unidad de observación: Un primer ciclo que, iniciado con una acelerada politización de las expresiones estudiantil-juveniles, culmina abruptamente en 1973 con la desactivación de los espacios de expresión colectiva y la demolición del escenario de interacción democrática; un segundo ciclo, caracterizado por la hegemonía pública de expresiones orgánicamente vinculadas a la dictadura que se desplegaban a la par de una subterránea articulación colectiva de expresiones estudiantil-juveniles opositoras parapetadas en la escena cultural dada la imposibilidad de su expresión político-pública; un tercer ciclo de reemergencia, re-politización y visibilidad pública de mundos juveniles con un fuerte componente contencioso y fuerte vínculo con campo político partidista en contrapelo al receso y las prohibiciones dictatoriales respecto a dicho campo; un cuarto ciclo de repliegue, de activismo estudiantil resistente (más que ofensivo) y de demandas acotadas, alejamiento del campo político formal e incipiente emergencia de ensayos organizativos politizados, despegado en paralelo al proceso de

\footnotetext{
${ }^{59}$ En el marco de la contienda electoral del año 2017 la candidatura presidencial del Frente Amplio, coalición en la cual se encontraron gran parte de las dirigencias y organizaciones emergidas del contexto de las movilizaciones de 2011, obtuvo con la figura de Beatriz Sánchez más de un 20\% del total de votos válidos en la elección presidencial. En el caso parlamentario, el conglomerado logró obtener 20 cupos para diputados y un cupo de senador, de los cuales más de 10 fueron encarnados en participantes directos de las movilizaciones estudiantiles de los últimos años. Antecedentes relativos a los principios, aspectos programáticos e integrantes del Frente Amplio pueden verse expuestos en http://www.frente-amplio.cl/

${ }^{60}$ En este texto se ha analizado el proceso chileno, pero naturalmente, hay influencias internacionales que repercuten en los movimientos o son procesadas de acuerdo a las ideas fuerzas presentes en cada periodo. El ciclo 1 los sesenta estuvieron marcados por la influencia de la revolución cubana y la explosión del poder joven expresado en eventos como el 68 francés y mexicano. El ciclo 2 se enmarca en el predominio de dictaduras militares en el cono sur, mientras que para la izquierda radical estudiantil la revolución nicaragüense de 1979 fue un importante punto de referencia para proyectar, durante el ciclo 3, movilizaciones y acciones que incluyeran un componente insurreccional. En el ciclo 4, las ideas críticas en torno a las vinculaciones de lo social y lo político partidario presentes en varios colectivos estudiantiles, tuvieron una referencia relevante en la irrupción zapatista de Chiapas en 1994. Y por último, es conocido el contexto internacional de acciones colectivas contenciosas a nivel global durante el 2011, que cubren experiencias tan diversas como la primavera árabe, el $15 \mathrm{M}$ español y las protestas contra los planes de austeridad durante la crisis griega.
} 
reconstrucción democrática institucional en Chile; un quinto ciclo, marcado por la reemergencia, la repolitización ascendente y la reactivación de formas colectivas de expresión pública de masas; y, por último, un ciclo -el actual- signado por la traducción del proceso de repolitización anterior en una intensa repartidización de las organizaciones estudiantil-juveniles, integradas ahora a la disputa política nacional.

Como es posible observar, las inflexiones, modificaciones, emergencias y reemergencias de la movimientalidad juvenil-estudiantil se encuentran claramente asociadas a lo largo de su historia con los procesos socio-políticos en los cuales ésta se ha insertado y, específicamente, con las formas de configuración del campo político-institucional. Lejos de ser una unidad de observación posible de ser analizada con independencia de su marco históricocontextual, la forma, intensidad y características específicas de dicha movimientalidad no pueden ser comprendidas si no es por medio de su inscripción en la historicidad sociopolítica.

Junto a lo anterior es posible señalar que, como una constante, el carácter político de la movimientalidad estudiantil-juvenil se encuentra presente en todos los ciclos acá observados. En cada una de sus etapas, estos movimientos expresan una determinada forma de ejercer la politicidad, evidenciando que el contenido y disposición política constituye una constante en las formas de despliegue de estos espacios de acción colectiva. Pero esta forma de ejercicio de la politicidad resulta diversa y variable, según las condiciones del contexto socio-político y según las capacidades y disposiciones contingentes de los movimientos: mientras en determinados ciclos la politización opera por medio de la incorporación a los espacios políticoinstitucionales, esto es, por medio de una partidización de su accionar (década de los sesenta, actualidad), existen otros momentos en los cuales la politización opera más bien en base a la separación respecto a dicho campo (post 1990). Y ello se evidencia, además, en formas diferenciadas de vinculación con lo público, las que van desde la partidización, la expresión contenciosa, la lógica corporativa o la acción colectiva retraída hacia el ámbito de la militancia cultural.

Como podemos ver, son distintas las formas de expresión de la movimientalidad juvenil-estudiantil a lo largo del período abordado. Sin embargo, estas distintas formas de expresión manifiestan como común denominador su referencialidad política, atributo éste que, a nuestro juicio y según hemos querido exponer a lo largo de este trabajo, constituyen el elemento de continuidad posible de observar en la deriva de este actor de la historia sociopolítica chilena.

\section{Bibliografía}

Aguilera, Oscar. Movidas, movilizaciones, y movimientos: cultura politica y politicas de las culturas juveniles en el Chile de hoy, Santiago, RIL, 2016.

Aguilera Oscar, Contreras Tamara, Guajardo Sergio, Zarzuri Raúl. La rebelión del coro. Análisis de las movilizaciones de los estudiantes secundarios, Santiago, documentos de trabajo CESC, 2006.

Agurto Irene, Canales Manuel, De la Maza Gonzalo. Irene Agurto, Manuel Canales, Gonzalo De la Maza (compiladores), Juventud chilena. Razones y subversiones, Santiago. Eco, Folico, Sepade, 1985.

Avendaño, Octavio. Octavio Avendaño, "Fracturas y representación política en el movimiento estudiantil: Chile 2011”, Última década 41, Valparaíso, CIDPA, 2014. 
Bellei, Cristian. El gran experimento. Mercado y privatización de la educación chilena, Santiago, Lom, 2015.

Cottet Pablo, Galvan Lidgia. Jóvenes, una conversación por cambiar, Santiago, ECO, 1993.

Donoso, Jorge y Dunlop Grace, Los 13 del 13. Los DC contra el golpe, Santiago, Ril, 2013.

Durán Carlos. "Campo político-institucional y procesamiento del malestar social en Chile, 1999-2009”, Izquierdas 40, Santiago, USACH IDEA, 2018.

Durán, Carlos. "El acontecimiento estudiantil y el viraje del proceso sociopolítico chileno", en Observatorio social de América Latina, 31, CLACSO, Buenos Aires, 2012.

García Monge Diego, Isla José, Toro Pablo. Diego García Monge, José Isla, Pablo, Los muchachos de antes. Historia de la FECH 1973 - 1988, Santiago, Universidad Alberto Hurtado, 2006.

García Huidobro, Juan Eduardo. “¿Qué nos dejó la movilización de los pingüinos?”, Nomadías 9, Santiago, Universidad de Chile, 2009.

Garretón, Manuel Antonio y Martínez, Javier (editores). Biblioteca del movimiento estudiantil, Santiago, Sur Profesionales, 1985.

Generación compiladores. Los jóvenes en Chile boy, CIDE, CIEPLAN, INCH, PSI PIRQUE, SUR. Santiago 1990.

Guzmán Errázuriz, Jaime. Escritos personales, Santiago, Fundación Jaime Guzmán, 2008.

González, Yanko. “El golpe generacional y la Secretaría Nacional de la Juventud: Purga, disciplinamiento y resocialización de las identidades juveniles bajo Pinochet (1973 - 1980), Atenea 512, Concepción, Universidad de Concepción, 2015, 87-111.

Guzmán Errázuriz, Jaime. Escritos personales, Santiago, Fundación Jaime Guzmán, 2008.

Hunneus, Carlos. El régimen de Pinochet, Santiago, Sudamericana, 2000.

Laclau, Ernesto. La Razón Populista, Buenos Aires, FCE, 2005.

Margulis, Mario y Urresti, Marcelo, "La juventud es más que una palabra", en Mario Margulis, La juventud es más que una palabra. Ensayos sobre cultura y juventud, Buenos Aires, Editorial Biblos, 1996.

Mattelart, Armand y Michele. Juventud chilena: rebeldía y conformismo, Santiago, Edición Universitaria, 1970.

Mella, Marcelo. "Composición, correlaciones de fuerza y elaboración de estrategias en el Pleno CONFECH (2011- 2015)", Última década 45, Valparaíso, CIDPA, 2016.

Moulian, Tomás. Chile actual. Anatomía de un mito, Santiago, Lom, 1997.

Moyano, Cristina. MAPU o la seducción del poder y la juventud, Santiago, Ediciones UAH, 2009

Moraga Valle Fabio. Fabio Moraga Valle, "Crisis y recomposición del movimiento estudiantil chileno 1990- 2001”, Renate Marsiske, Movimientos estudiantiles en la historia de América Latina Ill, México DF, UNAM. Plaza y Valdés, 2006. 
Morales, Mauricio, "La primera mujer Presidenta de Chile. ¿Qué explicó el triunfo de Michelle Bachelet en las elecciones de 2005-2006?, Latin American Research Review, 43: 1, 2008, 7-31.

Muñoz Tamayo, Víctor. ACU. Rescatando el asombro. Historia de la Agrupación Cultural Universitaria ${ }_{2}$ Santiago, Calabaza del Diablo, 2006.

Muñoz Tamayo, Víctor. Generaciones. Juventud universitaria e izquierdas políticas en Chile y México (Universidad de Chile-UNAM 1984-2006), Santiago, LOM, 2011.

Muñoz, Tamayo Víctor. "Movimiento social juvenil y eje cultural. Dos contextos de reconstrucción organizativa. (1976-1982, 1989-2002)", Última Década 17, Viña del Mar, CIDPA, 2002.

Muñoz Tamayo Víctor. "Chile es bandera y juventud. Efebolatría y gremialismo durante la primera etapa de la dictadura de Pinochet". (1973-1979)", Historia Crítica 54, Colombia, Universidad de los Andes, 2014

Muñoz Tamayo, Víctor. Historia de la UDI. Generaciones e historia política 1973 2013, Santiago, Universidad Alberto Hurtado, 2016.

Muñoz Tamayo, Víctor. "El Partido Socialista de Chile y la presente cultura de facciones. Un enfoque histórico generacional (1973 - 2015)", Iqquierdas, número 26, Santiago, USACH - IDEA, 2016.

Muñoz Tamayo, Víctor, y Aguilera, Oscar. "Preguntas por la juventud, preguntas por la política. Acción colectiva, movimientos sociales y militancia en los estudios de juventud. Chile 1967 - 2013”, Pablo Cottet editor, Juventudes. Metáforas del Chile contemporáneo, Sanriago, RIL, 2015, 69-103.

Navia, Patricio y José Izquierdo. Patricio Navia y José Izquierdo, “Cambio y continuidad en la elección de Bachelet", América Latina Hoy 46, Salamanca, Universidad de Salamanca, 2007.

Olguín Myriam. "La organización juvenil en el espacio parroquial. Comunidad, protesta y éxodo en los 80“, Proposiciones, Santiago, Sur, 1996.

Pairicán, Fernando. "La gran crisis: las Juventudes Comunistas de Chile defendiendo su identidad en tiempos de transición y renovación democrática 1989 1992”, Izquierdas 30, Santiago, USACH - IDEA, 2016.

Palieraki, Eugenia. "iLa revolución ya viene! El MIR chileno en los años sesenta", Santiago, LOM, 2014.

Paredes, Juan Pablo Paredes. La educación chilena no se vende jse defiende! La política de significación de la movilización por la Educación Pública en Chile. 2011-2013, Tesis para optar al Grado de Doctor en Ciencias Sociales, Santiago, Facultad de ciencias sociales, Universidad de Chile, 2015.

Poch, Pedro. Del mensaje a la acción. Construyendo el movimiento Hip Hop en Chile (1984, 2004 y más allá), Santiago, Quinto Elemento, 2011.

PNUD. Desarrollo Humano en Chile. Los tiempos de la politización. Santiago: Programa de las Naciones Unidas para el Desarrollo (PNUD), 2015.

Ponce, Camila. "De los libros a la calle: La transformación cultural y política de los jóvenes militantes chilenos a partir de las movilizaciones estudiantiles de 2011", tesis doctoral, École doctorale de l'EHESS, París, 2017.

Ramos, Ramón. "Problemas textuales y metodológicos de la sociología histórica”, Reis, vol. 63, n. 93, 1993. 
Ruiz, Carlos y Giorgio Boccardo. Los chilenos bajo el neoliberalismo. Clases y conflicto social, Fundación Nodo XXI y Ediciones El Desconcierto, 2014.

Salazar, Gabriel y Pinto, Julio. Historia Contemporánea de Chile V. Niñezy Juventud, Santiago, Lom, 2002.

Salazar Gabriel y Pinto Julio. (2002) Historia Contemporánea de Chile V. Niñezy Juventud. Lom. Santiago de Chile.

Santoni Alessandro. El comunismo italiano y la vía chilena. Los orígenes de un mito político, Santiago, Ril, 2011

Tarrow, Sidney. El poder en movimiento: Los movimientos sociales, la acción colectiva y la política, Madrid, Alianza Editorial,1998.

Thielemann, Luis. La anomalía de la transición. Movimiento estudiantil e izquierda universitaria en el Chile de los 90, Santiago, Tiempo Robado, 2016.

Thielemann, Luis. "Hijos de Recabarren, hijos de la transición: sobre las JJCC y la anomalía estudiantil de los 90", en Rolando Álvarez y Manuel Loyola, Un trébol de cuatro hojas. Las juventudes comunistas de Chile en el siglo XX, Santiago, Ariadna, 2014.

Valdivia, Verónica. Nacionales y Gremialistas. El parto de la nueva derecha política chilena 1964 1973, Santiago, LOM, 2008.

Valenzuela, Katia. "Colectivos juveniles: ¿inmadurez política o afirmación de otras políticas posibles?”, Última Década 26, Valparaíso, CIDPA, 2007.

Valenzuela, Eduardo. La rebelión de los jóvenes. Un estudio de anomia social, Santiago, Ediciones Sur, 1984.

Zarzuri, Raúl y Ganter, Rodrigo. Culturas Juveniles, Narrativas Minoritarias y Estéticas del Descontento, Santiago, Ediciones UCSH, 2002.

Documentos.

.- "Carta abierta de FEUC al presidente Allende". Documento firmado por el comité ejecutivo de FEUC: Javier Leturia, presidente; Alberto Hardessen, vicepresidente; Guillermo Correa, secretario general. Santiago, 3 de junio de 1973. Archivo Fundación Jaime Guzmán.

.- "Hacia una nueva institucionalidad a través de la renuncia de Allende". Declaración de: Federación de Estudiantes de la Universidad Católica de Chile FEUC, Federación de Estudiantes de la Universidad Católica de Valparaíso FEUC- V. Santiago, 29 de agosto de 1973. Archivo Fundación Jaime Guzmán.

.- "Decreto con Fuerza de Ley N- 1 de 30 de diciembre de 1980", publicado en: Revista Academia número 1, Santiago, Academia Superior de Ciencias Pedagógicas, 1981.

.- "Acuerdo CONFECH - MINEDUC", Santiago, 13 de septiembre de 2005, firmado por el ministro de educación Sergio Bitar y los representantes de CONFECH. En www.mineduc.cl 